\title{
O Serviço de Objetos do Museu Paulista'
}

\author{
Adilson José de Almeida \\ Angela Maria Gianeze Ribeiro \\ Heloisa Barbuy \\ Margarida Davina Andreatta \\ Museu Paulista da USP
}

Curadoria de acervos e sistema de informação

O Serviço de Objetos do Museu Paulista é responsável pela curadoria de todo o acervo de tridimensionais reunido na instituição desde a sua criação. Mais além, tal acervo tem sua origem mesmo antes de o Museu existir, uma vez que seus primeiros objetos provieram de coleções já anteriormente formadas na São Paulo do século XIX, principalmente da Coleção Sertório².

Oacervo de objetos atinge atualmente um total de 27.000 unidades, cuja entrada pode ter-se dado por doação, compra, herança (testamento ou herança vacante) ou coleta arqueológica. Cada objeto pode chegar individualmente ou como parte de um conjunto maior, composto por peças várias. No caso de conjuntos de objetos doados por uma família, indivíduo ou instituição, definem-se, tal como na arquivística, as chamadas coleções pessoais, cujo nome - do indivíduo, família ou instituição que as reuniu originalmente - será sempre mantido, podendo-se recuperar o todo a qualquer momento. Algumas das que contam com maior número de peças são as Coleções Santos Dumont, Olga de Souza Queiroz, José Carlos de Macedo Soares, Prado Guimarães, Carmencita Bettenfeld Julien e Força Pública.

Ao longo do tempo, conjuntos de objetos ligados a alguns movimentos históricos passaram também a ser usualmente referidos como coleções, constituindo coleções temáticas, como Coleção Independência, Coleção Guerra do Paraguai, Coleção Revolução de 32 (BASSO, 1999).

\begin{abstract}
1. O Serviço de Objetos é integrado por Heloisa Barbuy (supervisora), Adilson José deAlmeida (especialista em acervos militares), Angela Maria Gianeze Ribeiro (Setor de Numismática), Rosana Gimenes Aguilera (técnica de museu) e, para 20032004, também por MariaJúlia Estefânia Chelini, especialista em eventos, estritamente dedicada à organização do $7^{\circ}$ Colóquio da Associação Internacional de Museus de História. Conta com a colaboração constante de Margarida Davina Andreatta para o Setor de Arqueologia Histórica e Industrial e com a atuação de Maria José Elias para coletas de acervo em doação.
\end{abstract}


2. Coleção que constituía o museu particular do coronel Joaquim Sertório, que era mantido por seu proprietário e freqüentemente aberto a visitantes de passagem pela cidade. Ao adquirir o imóvel em que estava instalado esse museu, o coronel Francisco de Paula Mayrink comprou também a coleção, que doou em seguida ao Estado. Esta veio assim a integrar o acervo do Museu Paulista.
Para fins de curadoria dos acervos sob responsabilidade do Serviço de Objetos foram criadas 26 categorias, que constituem a base de organização documentária deste Serviço, correspondentes a coleções tipológicas, isto é, o critério de agrupamento de objetos, para fins de documentação de acervos, baseiase prioritariamente em suas características morfológicas e funcionais, o que tem implicações também em projetos de pesquisa. Assim é que um thesaurus para a organização das coleções tipológicas que compõem o acervo de objetos está ałualmente em desenvolvimento. Tem como critério central o aspecto funcional dos objetos, agrupados e subagrupados conforme o sistema de usos no qual se inserem Assim há, por exemplo, uma classe de objetos relativos ao processamento da alimentação, subdividida em objetos para tratamento e preparação, cozimento, serviço/consumo, conservação/guarda e utensilios de uso geral. No que diz respeito à indumentária, está dividida primeiramente em civil e oficial. A partir daí, em cada uma dessas duas classes, a documentação sobre as peças de vestuário se organiza de acordo com sua função básica de cobrir o corpo, conforme a parte do corpo a

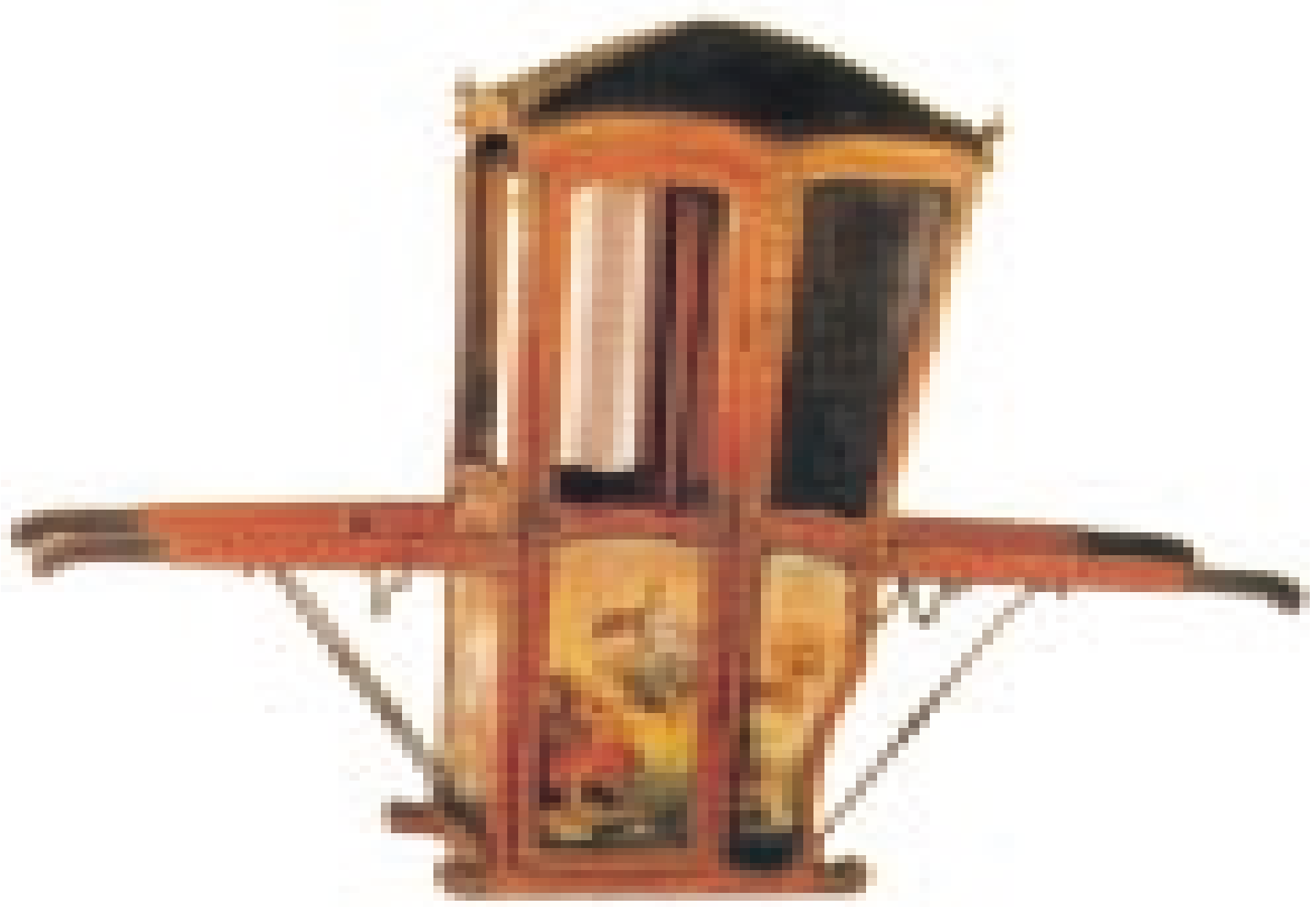

FIGURA 1 - Cadeirinha de arruar da segunda metade do século XVIII. Conforme Antonio Egidio Martins, pertenceu, originalmente, a frei Dom Manoel da Ressurreição, 3ํ Bispo de São Paulo (que viveu nesta cidade de 1774 até seu falecimento, em 1789), e não à Marquesa de Santos, como constou por várias décadas. Depois de passar pelas mãos de outros proprietários, foi doada, em 1886, ao Museu Sertório e, assim, veio a integrar o acervo do Museu Paulista desde o início desta instituição. Acervo Museu Paulista da USP. 
que se destinam ou a funções específicas para as quais foram concebidas: para cabeça, pescoço/costas, sobrevestimentas para o tronco, vestimentas de uso geral para o tronco, peças para braços/punhos/mãos, pernas/tornozelos/pés, roupas de baixo, roupas de dormir, roupas de bebê, indumentárias especiais. Para a coleção de mobiliário também se usam critérios funcionais, agrupando-se os móveis de acordo com suas finalidades de apoio e suporte, assento ou descanso, guarda e exposição e repouso, além de anteparos e espelhos (PAIXÃO, 1999). Quanto aos elementos de edificações, organizam-se de acordo com a função a que se destinaram nas construções para as quais foram concebidos: instalações hidráulicas, instalações elétricas, elementos estruturais, elementos ornamentais, elementos de alvenaria/ revestimento/piso, elementos de abertura (iluminação/ventilação/proteção/ vedação) e complementos de janelas e portas, além das maquetes e dos elementos funerários. E assim por diante.

A estrutura do thesaurus reflete-se no banco de dados e imagens desenvolvido na instituição e atualmente em fase de alimentação (BARBUY; LIMA; CARVALHO, 2002).

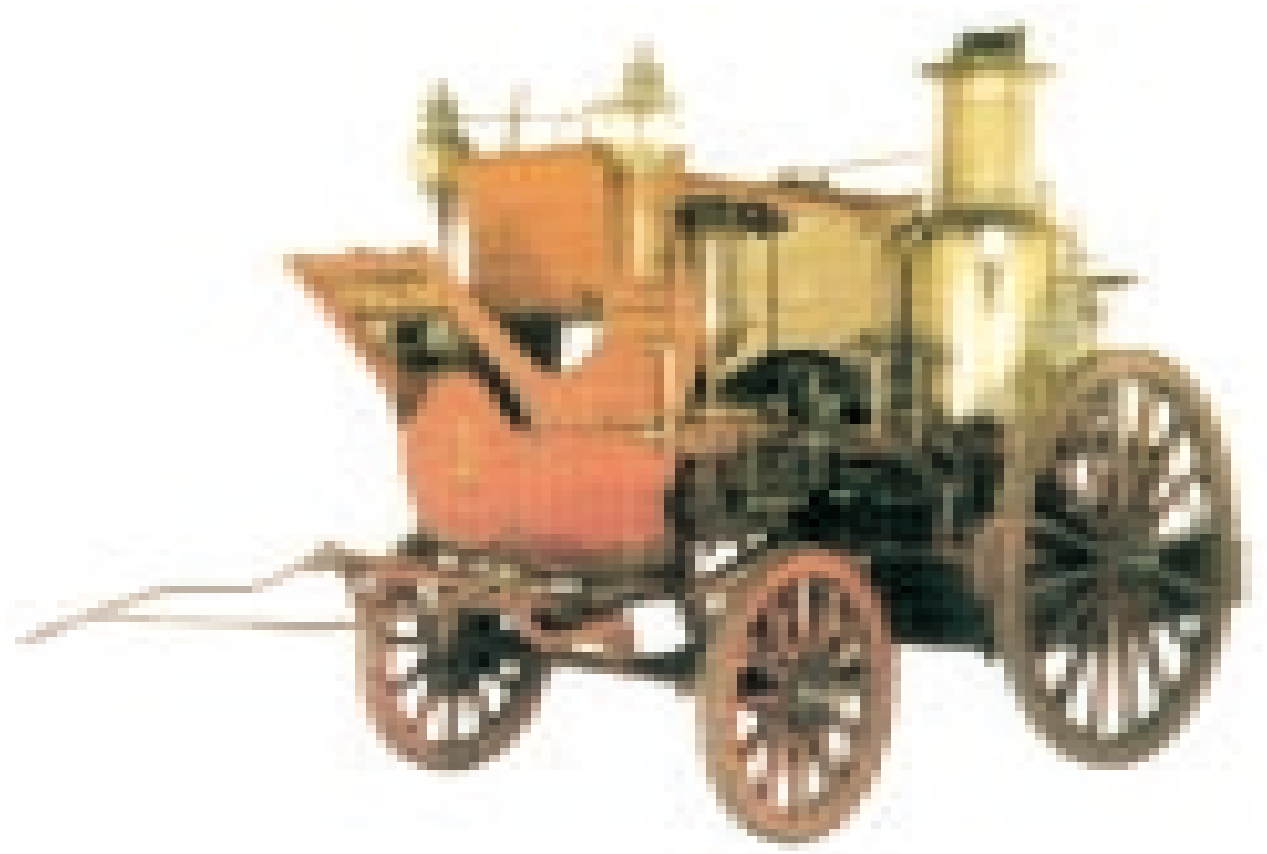

FIGURA 2 - Carro de bombeiros do final do século XIX, integrante da primeira frota do Corpo de Bombeiros de São Paulo. Trata-se de um carro-bomba, destinado a bombear água de rios e tanques e canalizá-la para incêndios por meio de mangueira. A pressão da água era provocada por vapor produzido pela caldeira, alimentada por carvão e lenha. Fabricado em Londres, Inglaterra, pela Merryweather \& Sons Fire Engine Makers, no modelo Greenwich, tinha capacidade para processar 1620 litros de água por minuto e produzir jatos de até 49 metros de altura. Recebeu, em São Paulo, o nome de Siqueira Campos, em homenagem ao chefe de polícia que muito havia contribuído para o desenvolvimento do Corpo de Bombeiros. Foi trazido para o Museu Paulista na década de 1950, por membros daquela corporação preocupados em preservar os últimos exemplares dos antigos carros. Acervo Museu Paulista dá USP. 


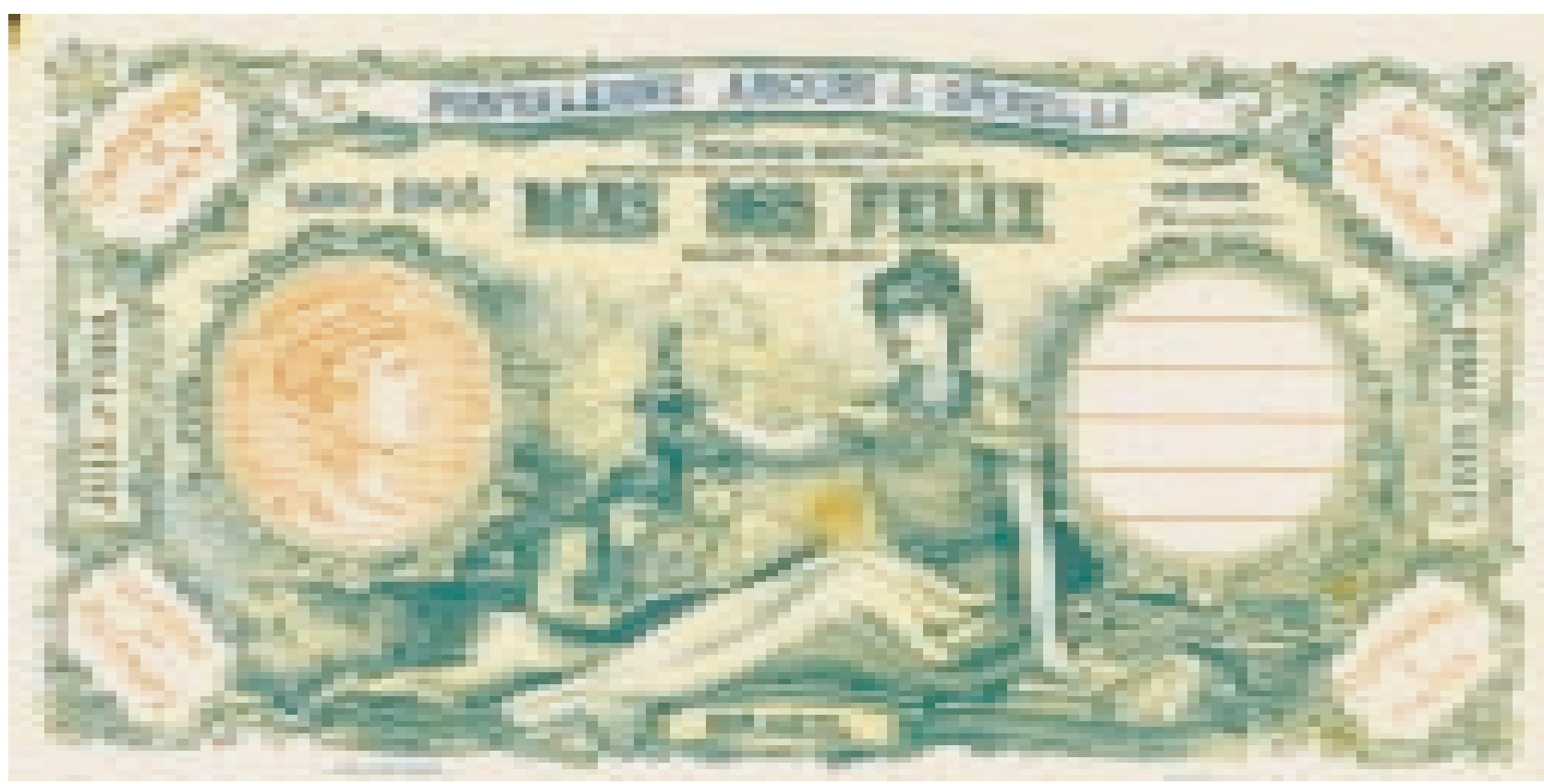

FIGURA 3 - Propaganda, em forma de cédula, da loja de materiais de construção de Pantaleone Arcuri \& Spinelli, em Juiz de Fora, MG, para o Ano Novo de 1905. Observe-se a paráfrase às cédulas oficiais: no lugar de "Thesouro Nacional" a propaganda se refere ao "Thesouro Natural", que garantirá a quantia de 365 dias felizes. Acervo Museu Paulista da USP.

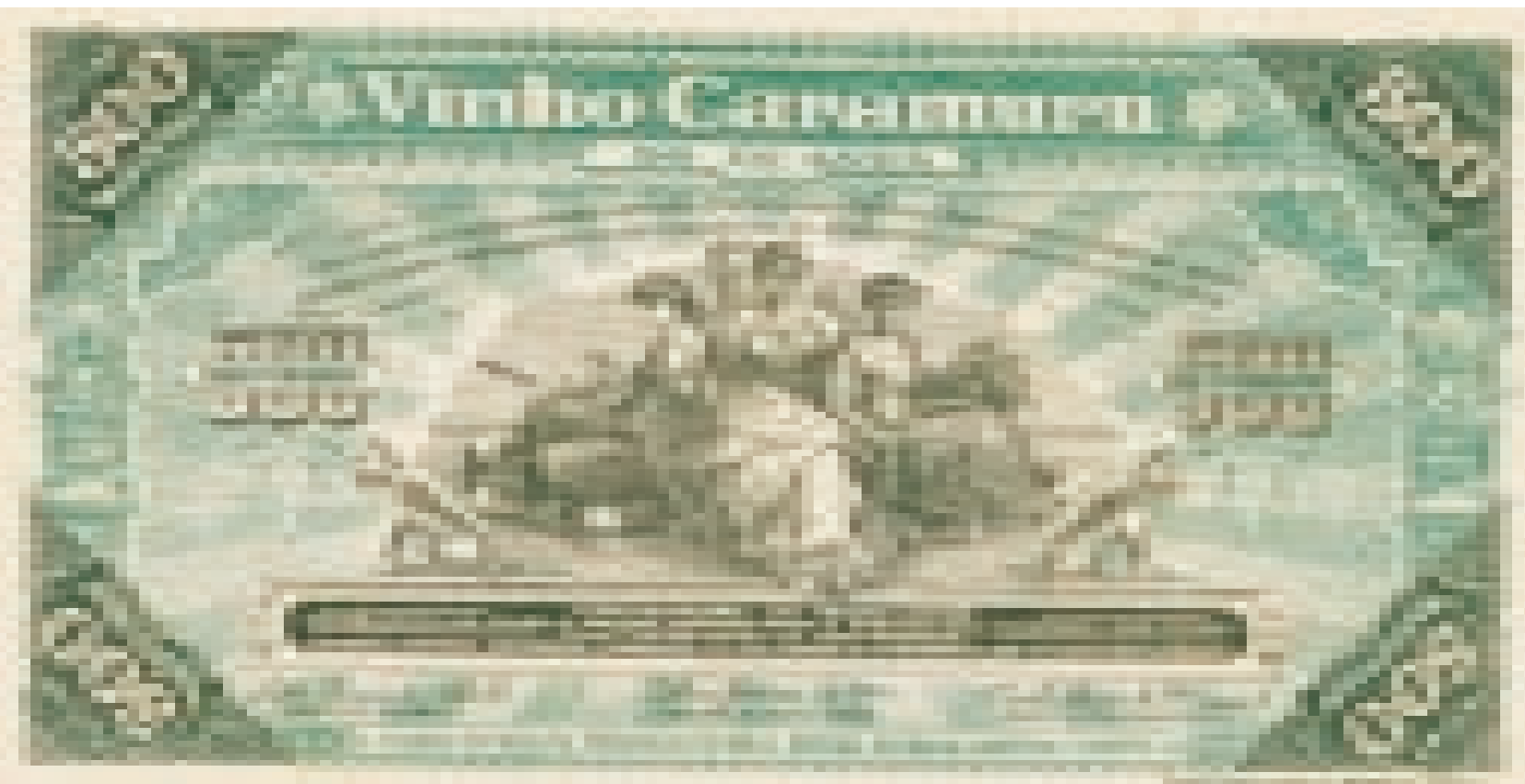

FIGURA 4 - Propaganda, em forma de cédula, do Vinho Caramurú, vinho medicinal fabricado pelo Dr. Assis em São Paulo, SP. No centro, legenda com os benefícios do preparado: Cura todas as emfermidades nervosas, Neurasthenia, Anemia, Impotencia ou fraqueza genital, perdas seminaes emfraquecimento da memoria ou da inteligencia, palpitações do coração etc. etc". Seu agente em São Paulo é a Casa Lebre, de Lebre Irmãos \& Mello, No reverso, o endereço da fábrica. Acervo Museu Paulista da USP. 


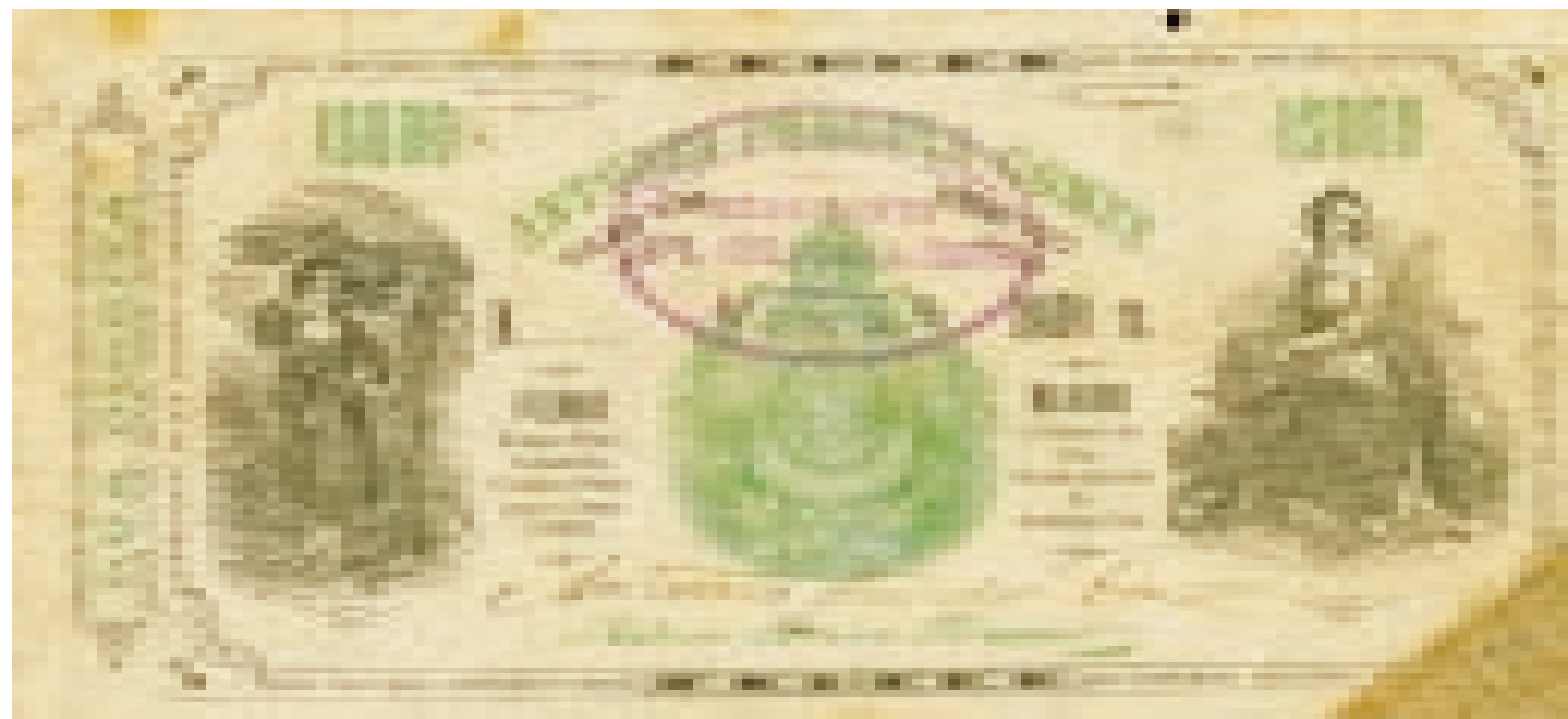

FIGURA 5 - Vale de Um mil Réis, na loja de Antonio Pereira Gomes em Arraial do Sagrado Coração de Jesus, MG. A loja vendia Fazendas, Roupas feitas, Armarinhos, Chapéos, Ferragens e Louça, Papel, além de Molhados e Gêneros do Paiz e Borracha. Acervo Museu Paulista da USP.

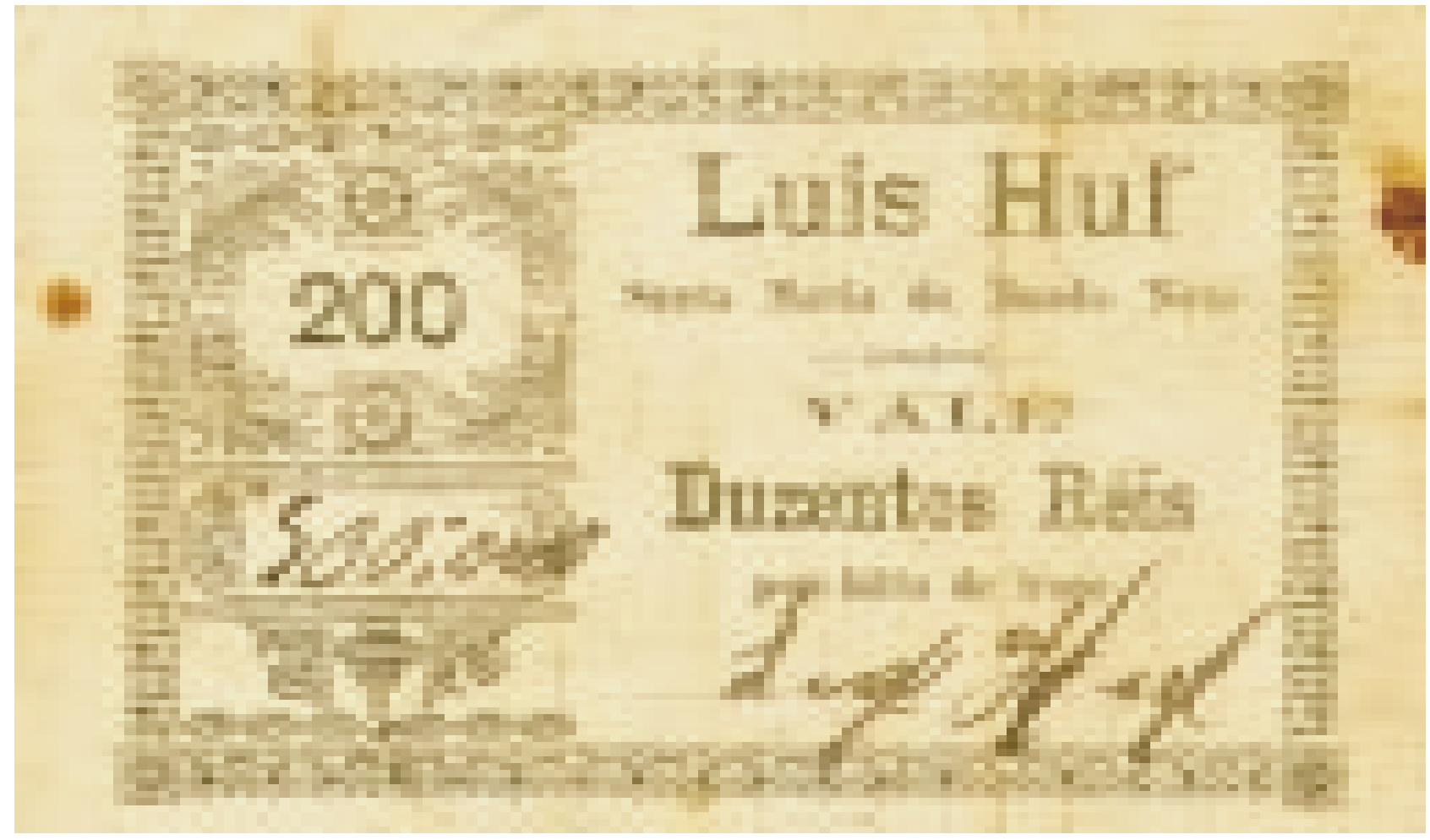

FIGURA 6 - Vale de Duzentos Réis, na loja de Luis Huf, em Santa Maria do Novo Mundo, PE. $O$ vale foi usado por falta de moedas de pequenos valores para troco. No reverso, carimbo com o valor: 200 Réis. Acervo Museu Paulista da USP. 
A alimentação do banco de dados é tarefa que exige trabalho intenso, longo e contínuo de toda uma equipe. Inicia-se com o registro administrativo de cada objeto, que ganha um número individual que o acompanhará sempre, e se desenvolve com a pesquisa dos dados referentes a cada objeto, processo que se dá em três níveis de catalogação, conforme o grau de aprofundamento das informações: sumário, médio e avançado. As providências básicas relativas à sua conservação física - higienização e acondicionamento - são tomadas de acordo com critérios e procedimentos previamente estabelecidos juntamente com o Serviço de Conservação e Restauração.

Para todo esse conjunto de trabalhos, o Serviço de Objetos tem contado com alunos de graduação da Universidade de São Paulo, na condição de bolsistas da Coseas e do Fundo da Pró-Reitoria de Cultura e Extensão. A colaboração desses estudantes, por um lado, já se tornou imprescindivel à necessária continuidade dos trabalhos de alimentação do Banco de Dados e, por outro, constitui experiência extremamente enriquecedora para os graduandos que, ao contribuírem para o desenvolvimento do sistema documental informatizado, encontram no trabalho uma oportunidade ímpar de aprendizado e experiência profissional: participam da equipe técnico-científica do Serviço, recebem orientação especializada para catalogação museológica e são introduzidos em História da Cultura Material, área científica do Museu Paulista.

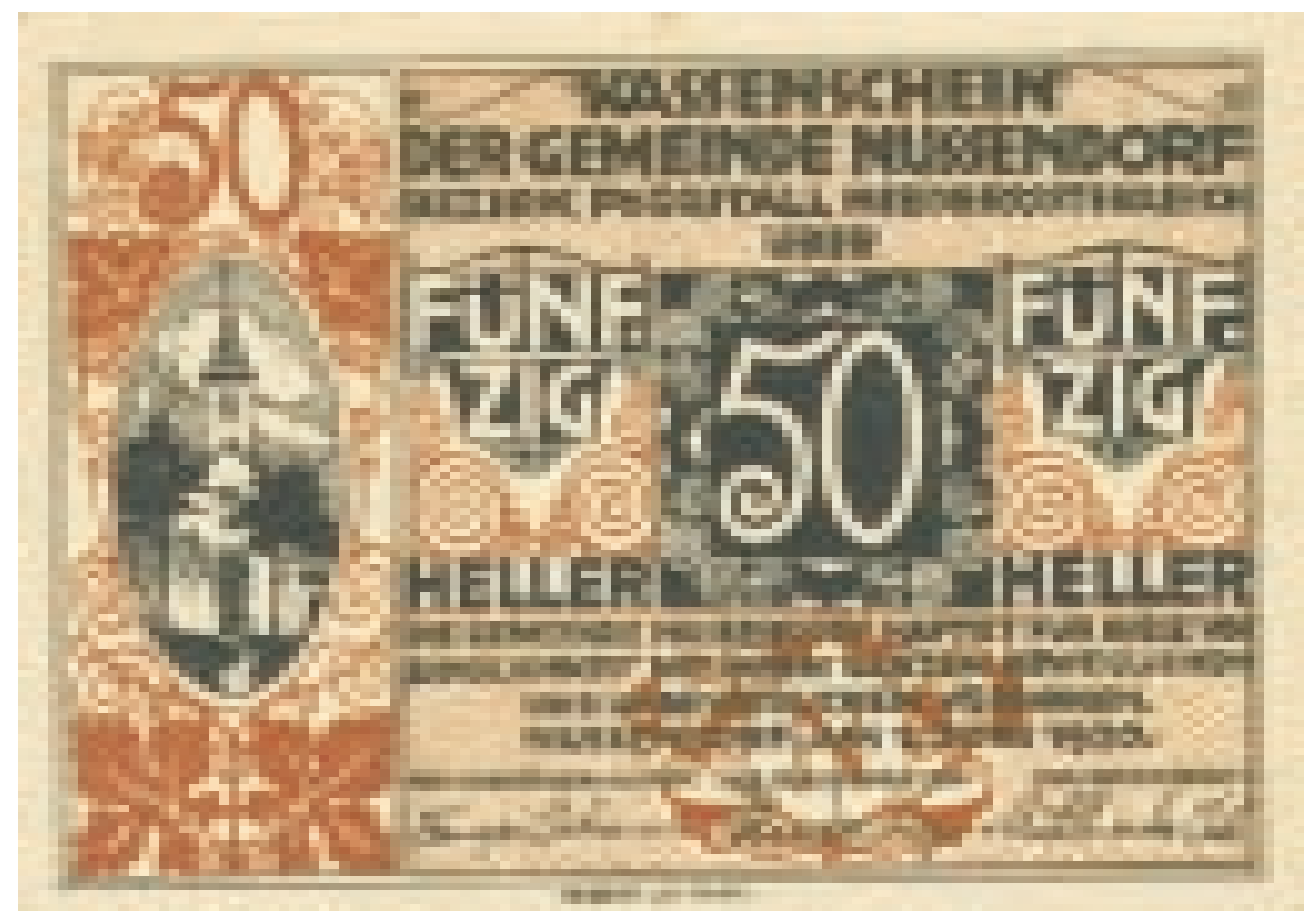

FIGURA 7 - Notgeld de Nussendorf, no valor de 50 Heller, 1920, com a imagem de uma construção da época romana, com as inscrições: "Certificado de registro financeiro da comunidade de Nussendorf, distrito de Pöggstall na Baixa Áustria" e "A comunidade de Nussendorf garantirá estas obrigações em suas fortunas totais móveis e imóveis - Nussendorf, em 1 de junho de 1920". Acervo Museu Paulista da USP. 


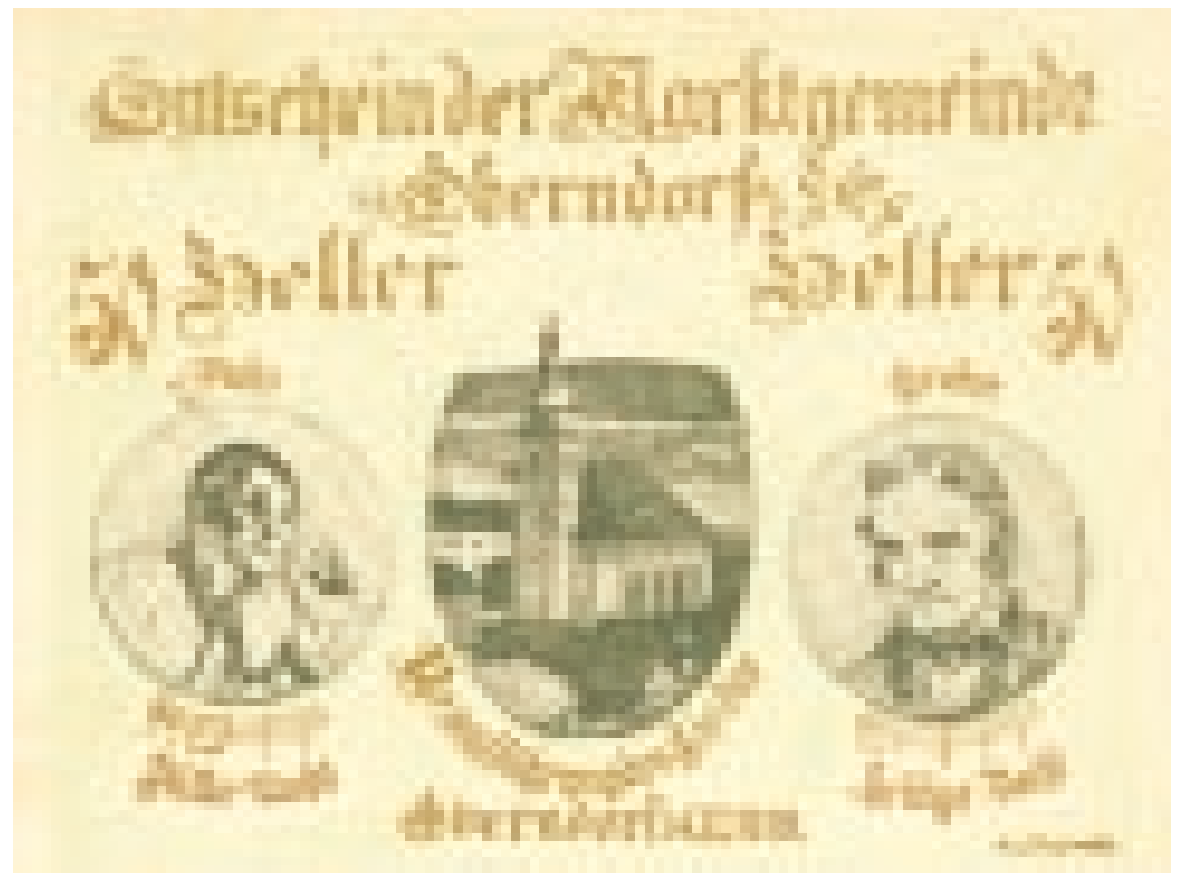

FIGURA 8 - Notgeld de Oberndorf, no valor de 50 Heller, 1920. Nas laterais, dois círculos com imagens dos compositores Joseph Mohr e Franz Gruber, autores da canção natalina Noite Feliz. Na parte superior a inscrição "Certificado do Mercado da Comunidade de Oberndorf", e na inferior a data da composição da canção; "Oberndorf, 24 XII 1818". Acervo Museu Paulista da USP.

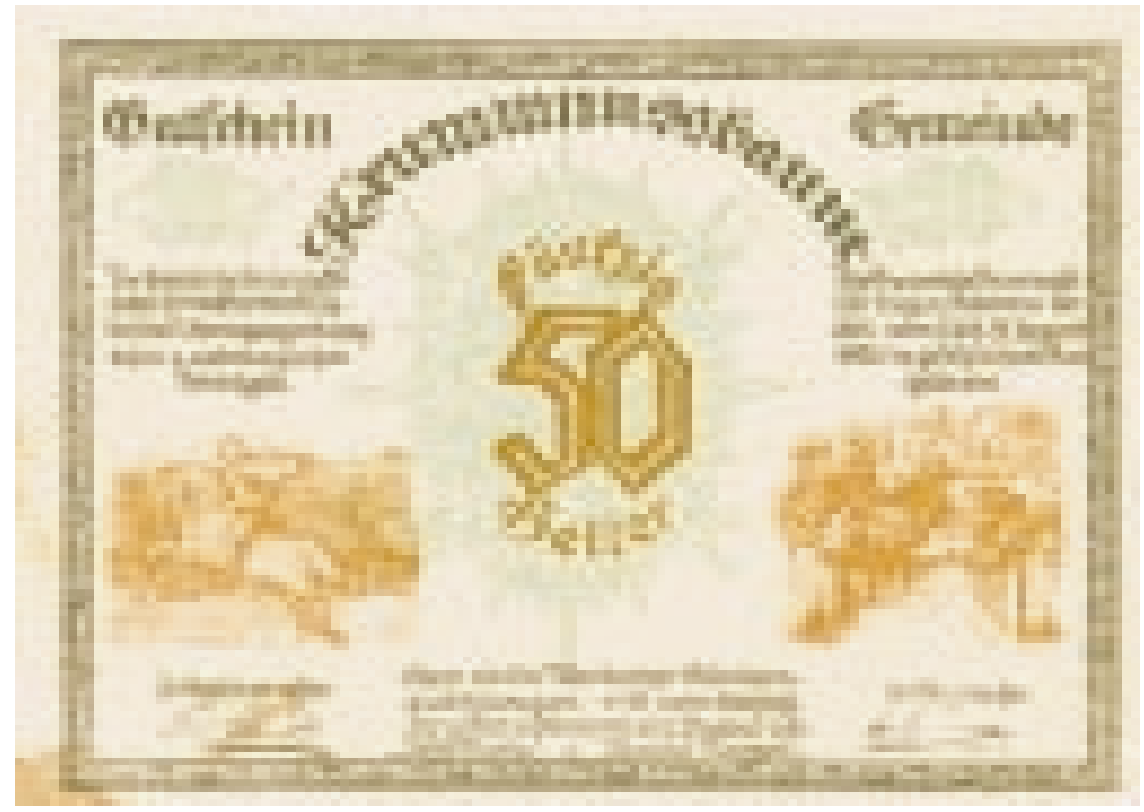

FIGURA 9 - Notgeld emitida na comunidade de Krummnussbaum, no valor de 50 Heller, válida até 31 de dezembro de 1920. Abaixo, um trecho da novela "Jeese und Maria", escrita por Enrica Handel-Mazzetti, em 1427, e nas laterais imagens relativas ao trecho citado. A novela é ambientada nessa comunidade. Acervo Museu Paulista da USP. 
3. $R G=$ registro geral, número de tombo interno.

4. Desde sua inauguração até a gestão Taunay, o Museu Paulista era primordialmente um museu de história natural, embora contasse já com uma seção de História e o edifício constituísse monumento à Independência.
Linhas de pesquisa

Filiando-se às três linhas de pesquisa institucionais - Cotidiano e Sociedade, Universo do Trabalho, História do Imaginário - e, em alguns casos, situando-se em suas intersecções, desenvolvem-se, no Serviço de Objetos, algumas sublinhas de pesquisa:

Sublinha de pesquisa 1 - Formação das coleções

Num museu de História Social, que trabalha na perspectiva da História da Cultura - e Cultura Material - ao se iniciar pesquisa em torno de uma coleção tipológica é preciso compreender, antes de mais nada, os contextos de sua formação.

Os estudos de Cultura Material usualmente analisam "sistemas de objetos" para compreender uma dada formação sócio-histórica. Entretanto, quando se trata de uma coleção de museu, isto é, de um "sistema de objetos" forjado artificialmente numa circunscrição institucional, em processos de seleção e interpretação de objetosdocumento, de acordo com critérios intelectuais predefinidos (claros ou não), a compreensão do contexto - ou contextos - de formação da coleção e de seus usos na instituição é passagem obrigatória para o estudo desses mesmos objetos em seus contextos sócio-históricos de origem e de usos precedentes.

\section{Ontologia museológica: o caso da Coleção de Veículos}

Tomemos como exemplo o caso da coleção de veículos do Museu Paulista (BARBUY, 2000), que está entre as mais antigas da instituição: iniciou-se o estudo sobre sua formação, esboçando-se como ponto de partida um quadro de origem, procedência, ano e forma de aquisição, pela instituição, desse objetos, a partir do qual se podem extrair algumas indicações.

A primeira delas é que mesmo anteriormente à gestão quase trintenária de Affonso de E. Taunay (de 1917 a 1945), em que o acervo histórico viria a ser altamente fomentado, registrava-se já a entrada de pelo menos quatro veículos, sendo uma liteira, duas cadeirinhas de arruar e uma cadeirinha-serpentina. Uma das cadeirinhas de arruar (RG 90) ${ }^{3}$ veio como parte integrante da Coleção Sertório, primeiro núcleo de acervo do Museu Paulista, o que pode ter apontado para uma inha a ser seguida (FIGURA 1). Ressalte-se que as outras três ingressaram no Museu por meio de compra, o que reforça a idéia de um real interesse da instituição por este tipo de objeto. Assim, vale a pena investigar as motivações que levaram à valorização de liteiras e cadeirinhas num período em que o acervo histórico do Museu era a menor parte e não sofria um fomento espetacular ${ }^{4}$.

Um apreço generalizado por um certo "valor de antigüidade", noção difusa que no senso comum conferia (e confere) valor a um objeto simplesmente por seu longo tempo de existência, por estar já fora de uso, por ter pertencido a sociedades passadas. Seria aquilo a que, em 1903, Alois Riegl chamou de "valor histórico", isto é: a importância que se atribui a "tudo o que foi, e hoje não é mais" (RIEGL, 1989, p. 18). 


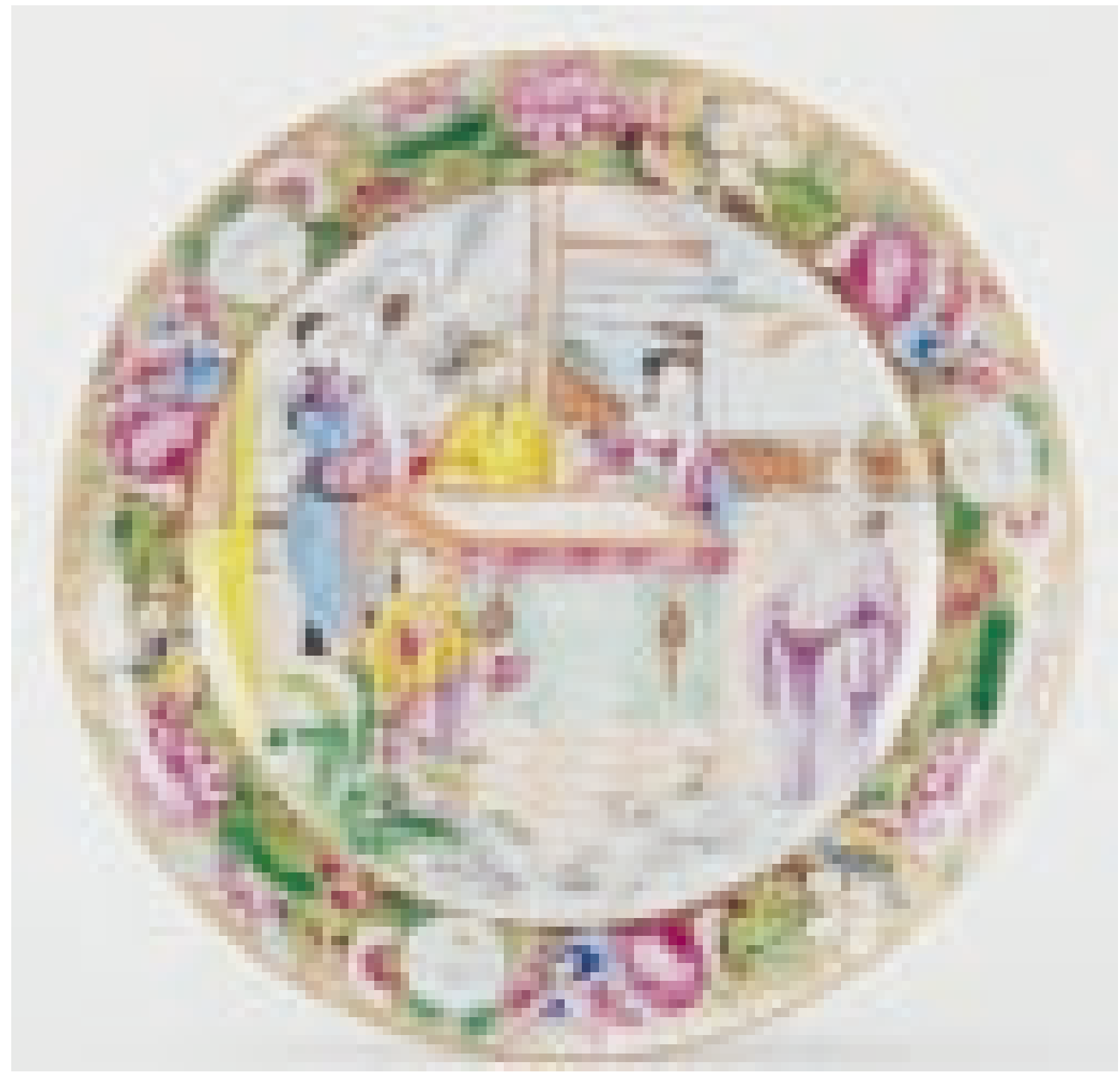

FIGURA 10 - Prato decorativo em porcelana chinesa, dita Companhia das Índias, produzida no período da dinastia Xianfeng, século XIX. Pertenceu a Marcelino de Avelar Almeida, Barão de Massambará (1 822-1898). Acervo Museu Paulista da USP. 
O fato de tais liteiras e cadeirinhas terem sido utilizadas apenas por uma elite pode tê-las revestido, desde seus tempos de uso, de um "valor de excepcionalidade". Em razão desta mesma excepcionalidade receberam, em geral, em sua confecção, o melhor que se podia dar em materiais, em trabalho artesanal, em preocupação estética, o que lhes faria atribuir também um "valor de refinamento".

A conjunção de valores de que se revestiram esses objetos, tornandoos dignos, aos olhos dos curadores que procederam a seu tombamento, de pertencer a um museu, poderia ser chamada de "valor museológico".

Um segundo ponto a observar diz respeito à perduração do interesse desempenhado na instituição por esse tipo de objeto, que se reflete no fato de terse continuado a adquiri-los - inclusive por compra - nas décadas de 1930 e 1940, e de terem sido sempre mantidos em exposição, a não ser quando em muito mav estado de conservação.

Em terceiro lugar, a predominância da procedência paulista faz relacioná-los à forte tônica de construção da História de São Paulo, que sempre

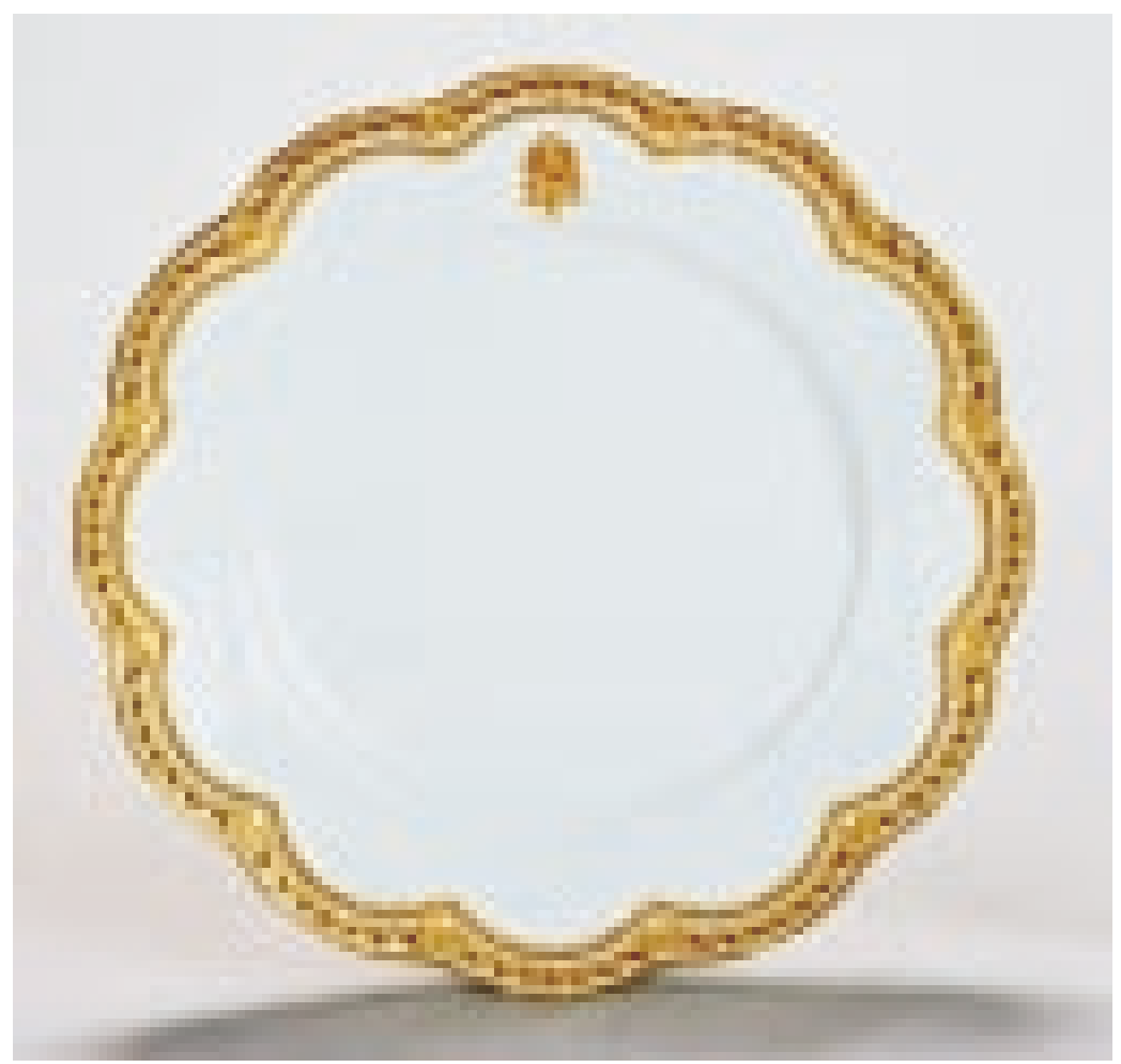

FIGURA 11 - Prato raso em porcelana francesa, produzida na manufatura Haviland \& $C^{\circ}$, de Limoges, na segunda metade do século XIX. Pertenceu a José Martins Pinheiro, Barão de Lagoa Dourada (1801-1876), de quem traz o monograma "JMP". Acervo Museu Paulista da USP. 
informou as pesquisas e demais atividades do Museu Paulista mesmo quando se tratou da História Nacional, conforme já bastante observado.

Foi esta ênfase paulista que trouxe também, por certo, para o acervo do Museu, na década de 1950, os quatro carros de serviços públicos de São Paulo, o que se fez, provavelmente, na esteira das amplas comemorações do IV Centenário da capital (FIGURA 2).

Como estamos vendo, a coleção é um bom indicador para a compreensão da visão que presidiu a formação do acervo no Museu Paulista no passado.

O didatismo que fez parte da filosofia do Museu ao longo de várias décadas pode explicar também alguns pontos. $\bigcirc$ propósito de mostrar uma evolução dos meios de transporte foi o que provavelmente motivou a reconstrução de uma serpentina com rede vinda de ltu/SP, varal e cambitos de Mariana/MG (RGs 84, 5595, 3541/3542), além dos bastões com ganchos e do cortinado com dossel que se vê em fotos lestes últimos provavelmente réplicas) para se dar presença a um meio de transporte de uso mais antigo do que as liteiras e cadeirinhas, e mais difundido do que estas no Brasil dos séculos XVI e XVII. E deve ter sido o que levou a distribuí-los em seqüência na Galeria Inferior Oeste, representando uma evolução no tempo e permitindo um exame comparado.

A propósito, a autenticidade dos objetos - um "valor de originalidade" que normalmente faz parte dos códigos ontológicos implícitos nos museus - , não parece ter tido grande importância no Museu Paulista, ou pelo menos não no Museu Paulista de Affonso Taunay. Quem trabalha na instituição sabe que algumas réplicas foram feitas e várias reconstituições parciais foram executadas no acervo. Isto, no entanto, não deve ser percebido de maneira simplista, reduzindo-se tal prática a mera incúria ou falsidade, como se tende às vezes a fazer. Esse procedimento se deve também ao partido didatista adotado por Taunay, no qual mais valia um sucedâneo do que a lacuna, no intuito pedagógico de ensinar a História pela visão da imagem e do objeto palpável. Aliás, na gestão Taunay, os objetos eram utilizados em caráter exemplificativo e não propriamente documental, o que fica claro pela falta de exames e estudos técnicos mais apurados dos acervos tridimensionais, mesmo num tempo em que se trabalhava intensa e organizadamente na instituição e em que se conferia grande valor a esses objetos. Tais estudos só começariam a ser feitos um pouco mais tarde, em 1948, quando o pintordocumentarista José Wasth Rodrigues (que trabalhara também com Taunay) procederia ao exame e descrições dos móveis e dos veículos, para fins de tombamento pela União (WASTHH RODRIGUES, 1948).

Um outro ponto sobre a considerar é o da categorização que cria uma coleção. $O$ próprio agrupamento aqui adotado - coleção de veículos terrestres é relativo e prende-se à perspectiva em que as unidades que a compõem foram reunidas e sempre apresentadas no Museu Paulista. Poder-se-iam criar diferentes agrupamentos. As cadeirinhas, se ligadas à idéia de seu espaço de uso, restrito às cidades, podem ser estudadas separadamente das liteiras, mais próprias para grandes percursos, fora dos circuitos urbanos. Os carros de serviços públicos também poderiam formar um núcleo à parte, e assim por diante. Uso urbano e uso rural; uso público e uso privado; uso individual e uso coletivo - são todos recortes possíveis como critérios para a criação de categorias. Enfim, as coleções, como 
5.Ashmolean Museum,fundado em 1683, considerado o primeiro museu moderno, cuja inauguração do Gabinete de Moedas data de 1884; British Museum, que já tinha moedas e medalhas na época de sua abertura em 1759; MuseuArqueológico Nacional de Madrid, que tem um gabinete numismático desde 1711. No Brasil, ver Museu Histórico Nacional do Rio de Janeiro e Museu Paranaense.Ambos tinham moedas e medalhas em seus acervos de fundação e passaram da condição de "depósitos" de antigüidades a centros de pesquisa, a partir do início do século XX. sistemas de objetos artificialmente articulados nos museus, podem formar-se a partir de critérios vários. E nunca é demais repetir que os estudos posteriores que delas se utilizem não precisam necessariamente seguir os critérios que as agruparam, podendo abordar seus componentes em outros sentidos.

\section{Setor de Numismática}

De um modo geral, pode-se afirmar que não há grande museu de história que não tenha o seu "gabinete numismático". Deixando de lado as práticas colecionistas da Antigüidade e da Idade Média, o que interessa nesta sublinha de pesquisa é contribuir para uma melhor compreensão de alguns aspectos dos museus históricos modernos ${ }^{5}$, entre os quais se situa o Museu Paulista.

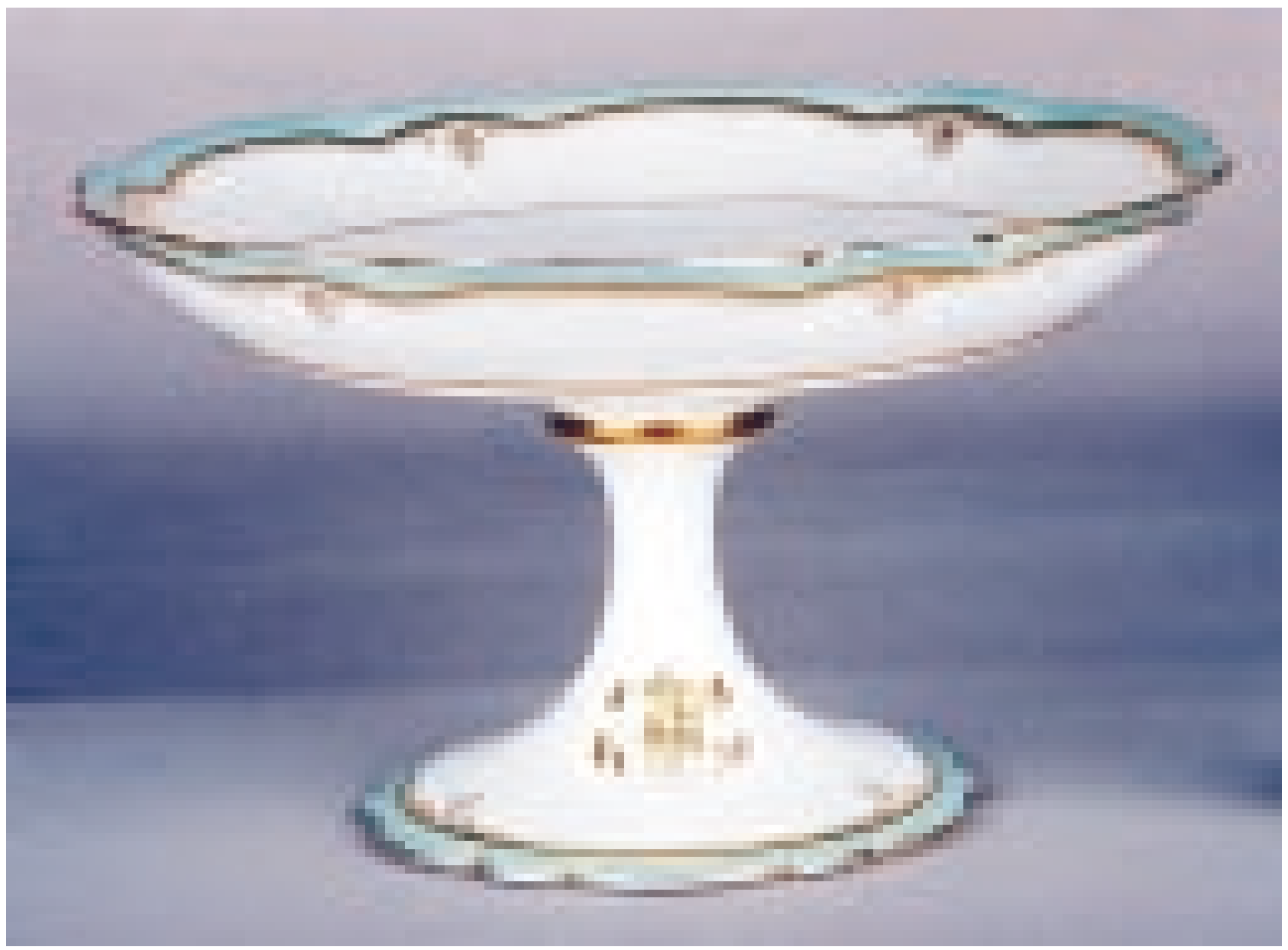

FIGURA 12 - Fruteira em porcelana francesa, comercializada pela Casa Gauvain, em Paris, no século XIX. Pertenceu a Anna Joaquina do Prado Fonseca, $2^{a}$ Baronesa de Jundiaí, de quem traz o monograma "AJPF". Acervo Museu Paulista da USP. 
Através de estudos sobre a formação do Setor de Numismática e suas coleções, pretende-se esclarecer, antes de mais nada, quais os critérios e conseqüentes procedimentos adotados, ao longo do tempo, para essa parte do acervo.

Já é possível apontar as linhas gerais de desenvolvimento desse Setor, que além da própria numismática, inclui também a medalhística ${ }^{b}$ e a filatelia, todos os três campos muito tradicionais dos museus de história.

Uma centena de peças numismáticas já existia no antigo "Museu Sertório", um das coleções que viriam a formar o núcleo inicial de acervo do Museu Paulista.

Em 1894, quando essas coleções foram transferidas para o edifício do lpiranga, do recém-criado Museu Paulista, já houve a incumbência de se classificar a coleção de numismática. Esse trabalho foi realizado por um naturalista, estendendo-se os critérios de um museu de história natural às coleções históricas.

Nas duas décadas seguintes, as coleções históricas tiveram um maior incremento e os relatórios institucionais de 1922/25 passam a citar as coleções de numismática, ainda não muito representativas, porém prestando-se já a consultas.
6. Alguns autores, como Mário Gomes Marques (1982), consideram objeto de estudo da numis-mática somente peças que tenham um valor libe-ratório, excluindo assim as medalhas e outros objetos monetiformes. Apesar de não ser este o conceito adotado pelo Museu Paulista, aqui também se distingue a numismática da medalhística, diferentemente da prática européia, onde inexiste a palavra"medalhística",englobando na Numismática também as medalhas (ou nos Gabinetes de Medalhas, as moedas).

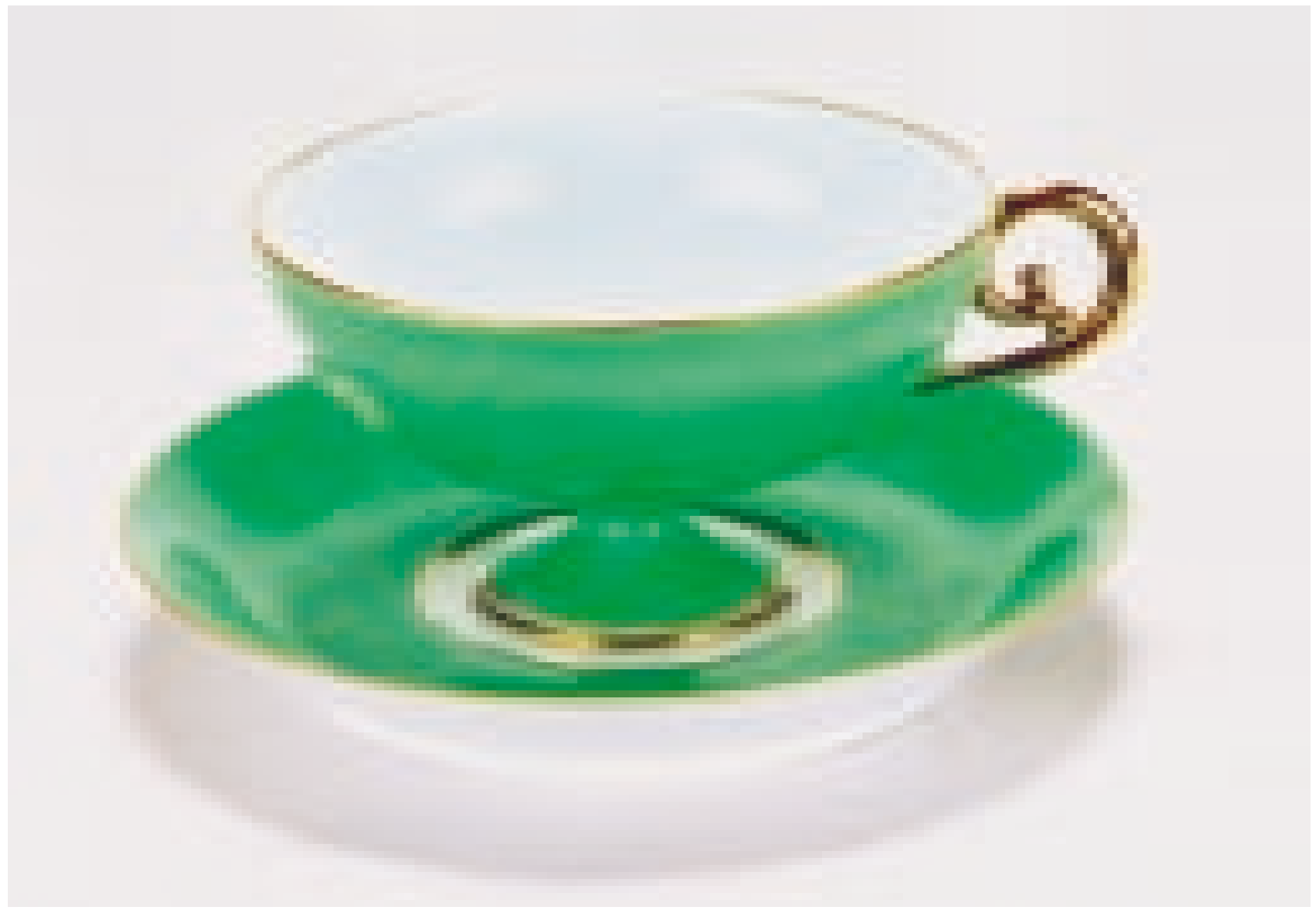

FIGURA 13 - Xícara de chá em porcelana francesa, produzida pela manufatura Pouyat, em Limoges, no padrão Cabaret Mousseline, com pintura em verde e dourado. Um serviço completo neste padrão foi apresentado pela primeira vez, todo branco, na Exposição Internacional de Londres, em 1862. Pertenceu aos Barões de Souza Queiroz e à sua filha Olga. Acervo Museu Paulista da USP. 
Assim, a coleção de numismática chega à década de 1940 com cerca de 9.000 peças, ampliando o universo de representação. Formalmente, porém, pode-se dizer que o Setor de Numismática só veio a se constituir como tal em 1946, na gestão do historiador Sérgio Buarque de Holanda, quando foi criado o primeiro cargo de numismata no Museu Paulista.

A partir de então, com a contratação de um numismata para cuidar e desenvolver a coleção, os critérios de aquisição e tratamento do acervo ficaram melhor estabelecidos. Enquanto para as demais áreas do Museu privilegiou-se a história nacional, para a consolidação do "gabinete de numismática" valorizou-se o universal, coerentemente com a concepção tradicional da área. Aliás, a maior parte dos atuais gabinetes de numismática também segue no mesmo sentido, ainda que eles sejam mais ou menos especializados em um ou outro tema: procuram adquirir exemplares que percorram a "história da moeda" em ordem cronológica, "melhorando" sempre suas coleções, do ponto de vista da conservação e aquisições de exemplares mais difíceis de se conseguir.

Hoje, a principal coleção do Setor de Numismática do Museu Paulista - mais numerosa e representativa - é a brasileira, que tem a responsabilidade de ser a maior coleção pública do Estado de São Paulo.

Justamente por situar-se num domínio extremamente especializado, que conta com conceitos, regras e práticas de curadoria solidamente estabelecidos, o Setor de Numismática tem-se engajado nos principais fóruns de discussão dessa área, especialmente naqueles a cujas tradições se acha mais diretamente ligado, que são os centros e grupos ibéricos e nacionais. Através dos encontros da International

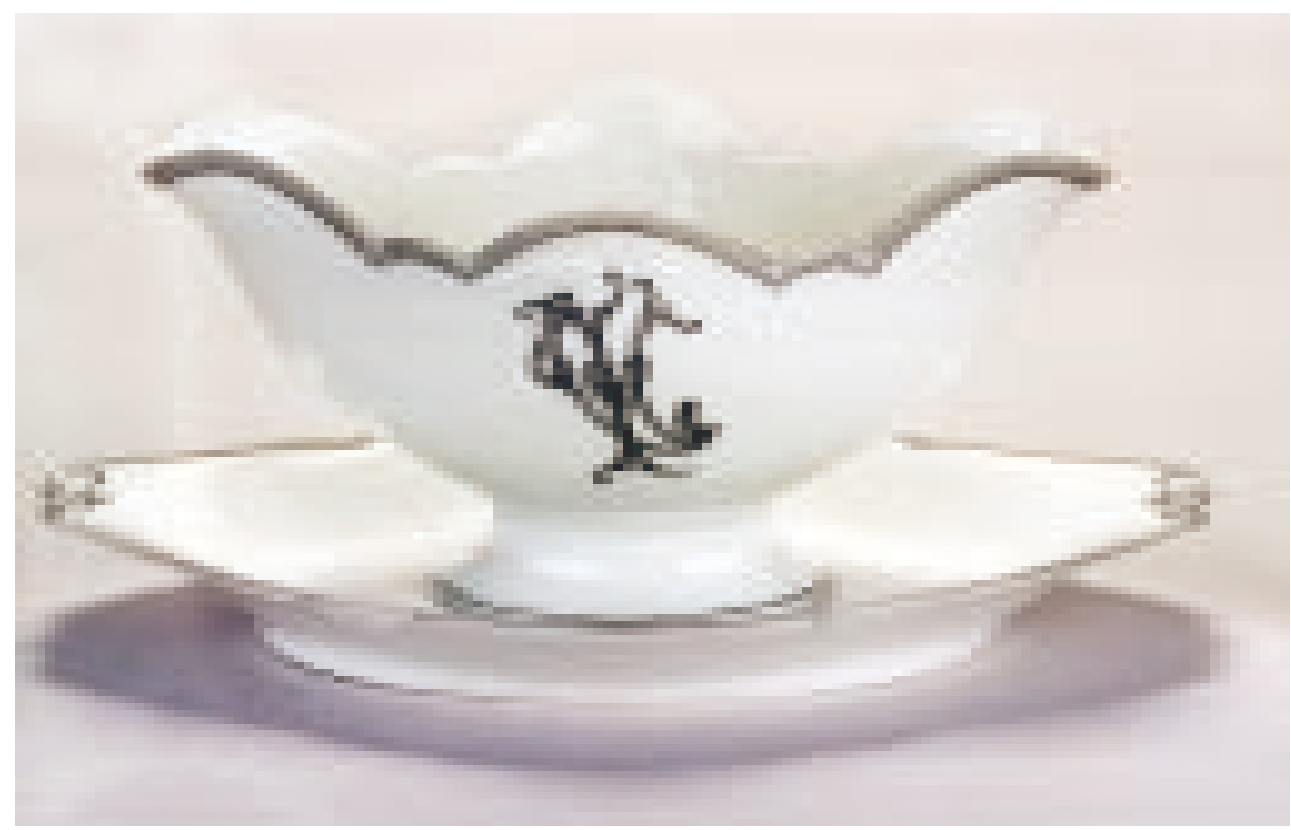

FIGURA 14 - Molheira em porcelana francesa, produzida pela manufatura de Martial Redon, em Limoges, e comercializada pela Casa Mansard, em Paris, no último quartel do século XIX. Pertenceu a Joaquim Bonifácio do Amaral, Visconde de Indaiatuba (1815-1884). Acervo Museu Paulista da USP. 
Numismatic Comission, do ICOMON - International Committee of Money and Banking Museums, da Sociedade Numismática Brasileira e Sociedade Portuguesa de Numismática Portuguesa, podem-se discernir as tendências atuais da pesquisa e curadoria em Numismática: metodologia para informatização de coleções, museologia da moeda, numismática e educação, formação das coleções. Esta última linha, embora não seja exclusiva dessa área, nela apresenta características bastante próprias, dada a grande difusão do modelo dos gabinetes numismáticos.

Sublinha de pesquisa 2 - Formas alternativas de dinheiro

Dentro do universo de estudos relativos à numismática são muito comuns os trabalhos centrados em um tipo numismático predeterminado, ou em um numerário cunhado em um dado período, ou ainda em exemplares únicos encontrados e

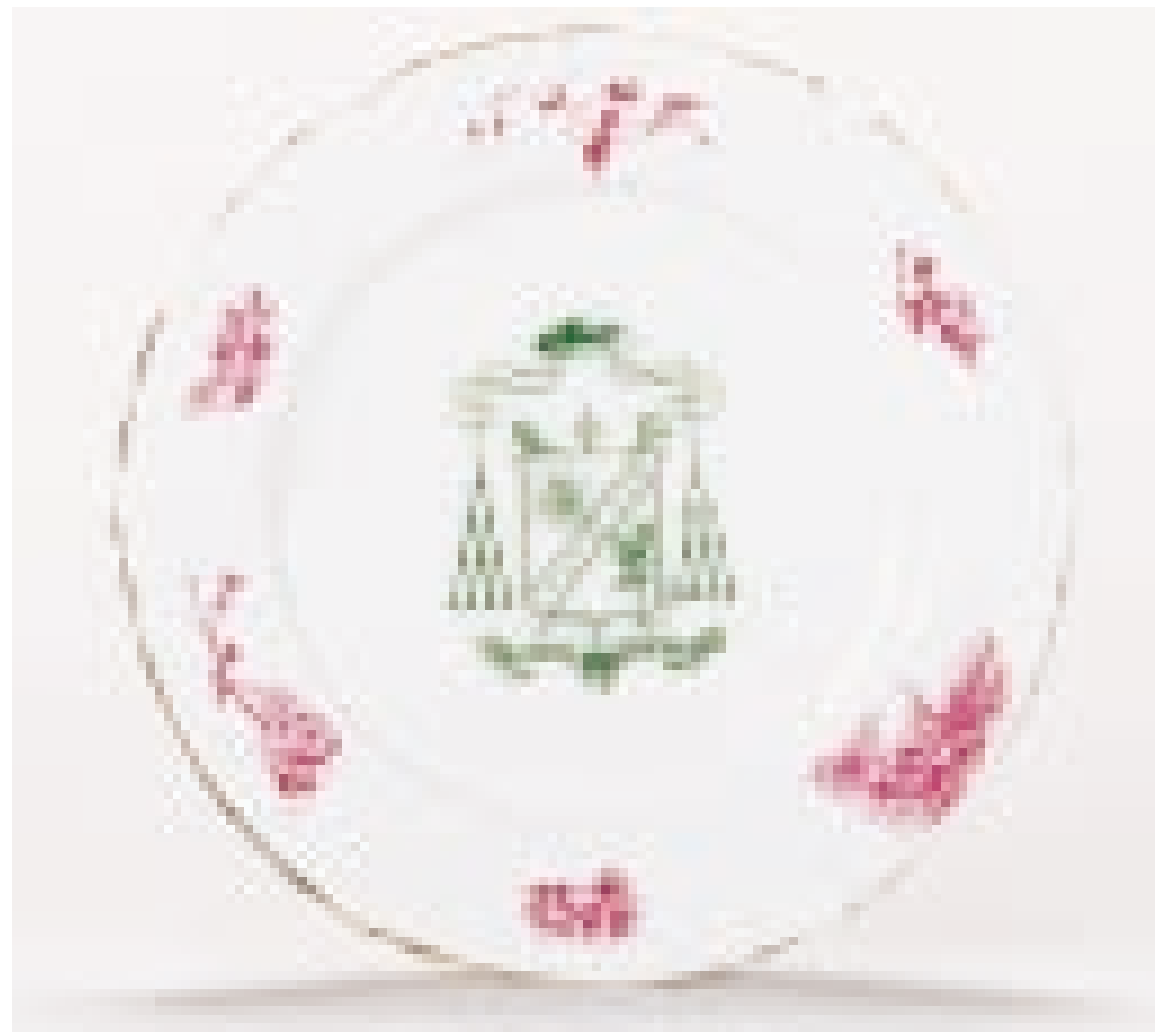

FIGURA 15 - Prato decorativo em porcelana portuguesa, produzido pela manufatura Vista Alegre, na cidade de mesmo nome. Pertenceu a Dom Duarte Leopoldo e Silva. (1 867-1938). Acervo Museu Paulista da USP. 


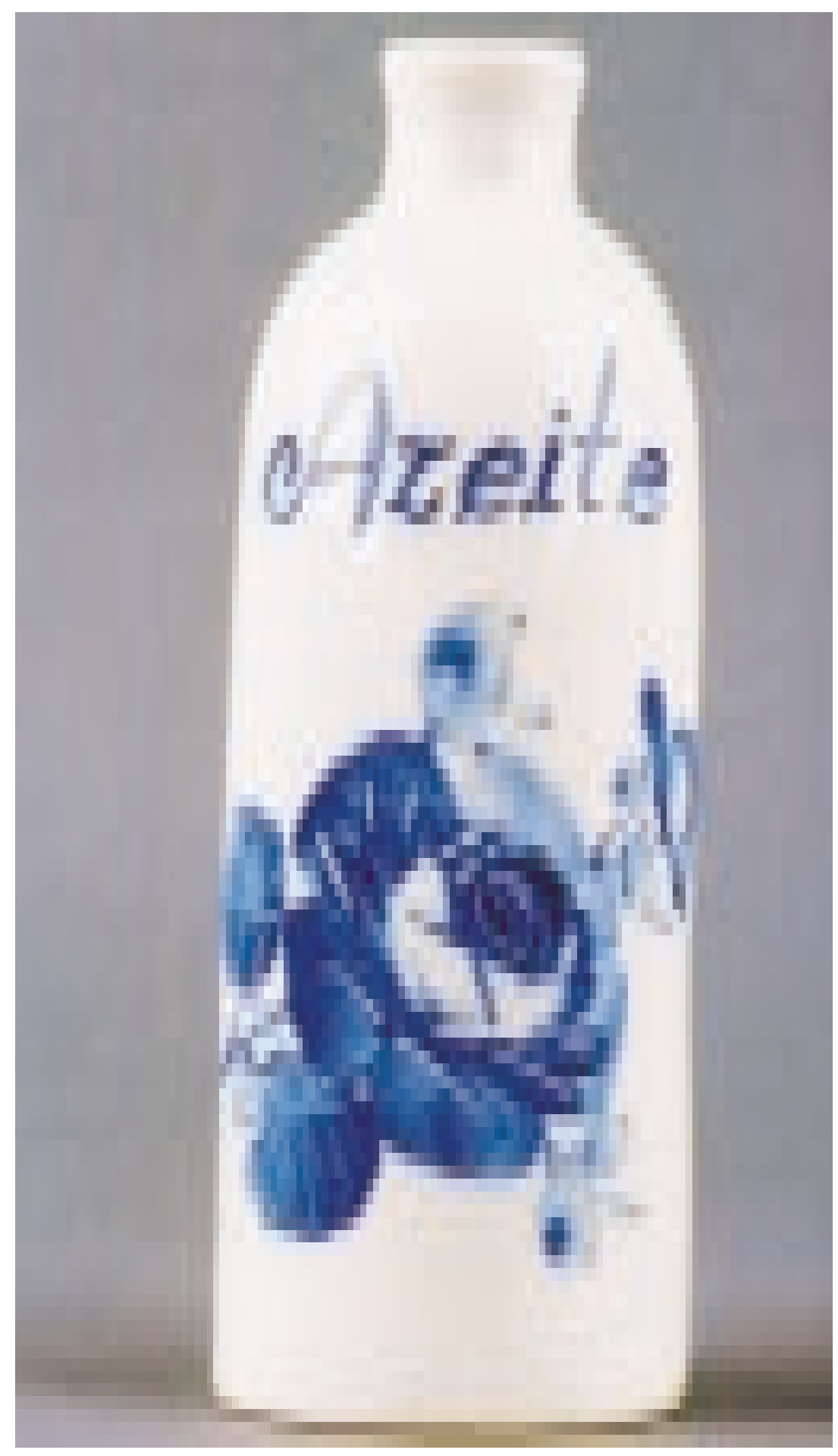

FIGURA 16 - Garrafa para azeite, de porcelana paulista, produzida pela Porcelana São Paulo (atual Teixeira), fundada pelos irmãos portugueses Virgílio e José Teixeira, em São Caetano do Sul, no ano de 1940. Acervo Museu Paulista da USP. 


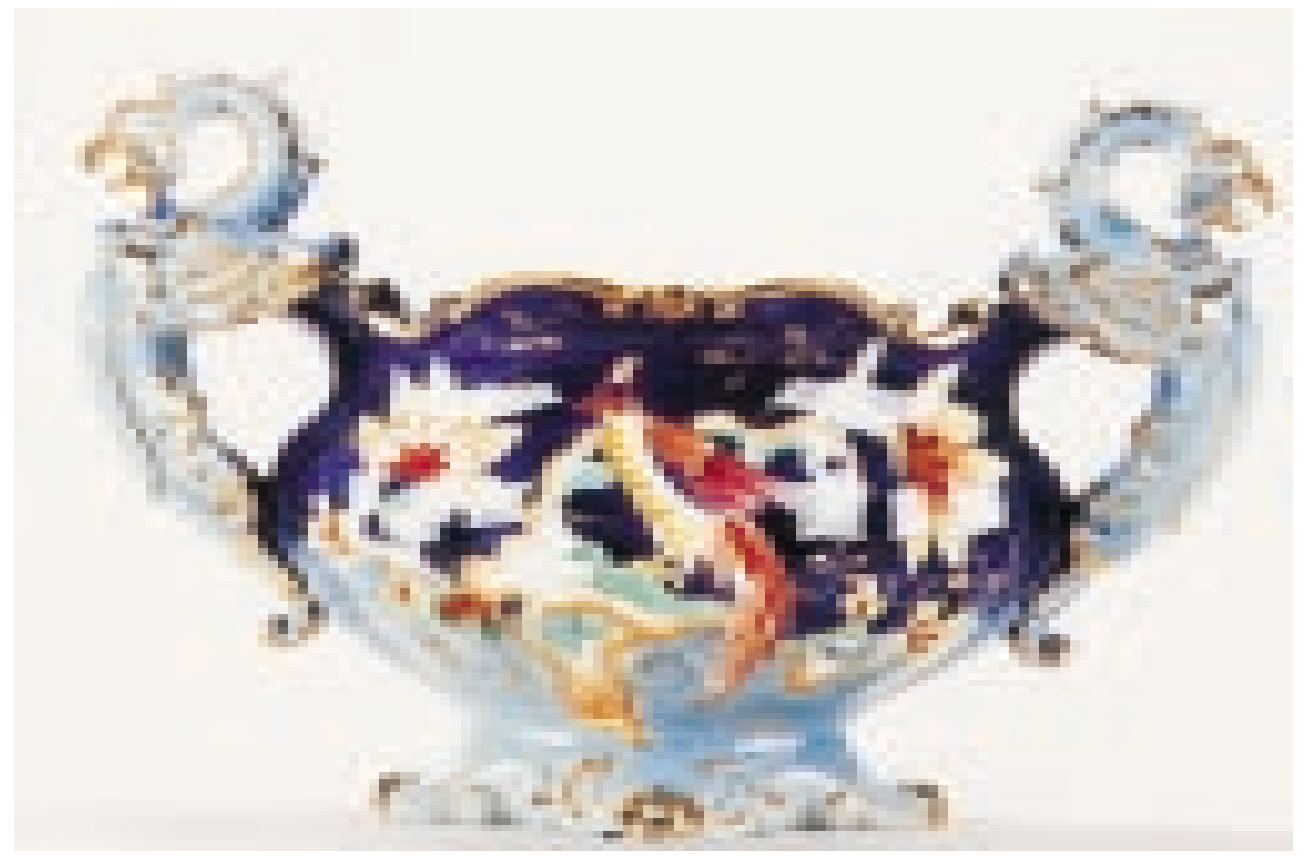

FIGURA 17 - Floreira em faiança paulista, pó-de-pedra, produzida pela Indústria de Louças Zappi S/A, na década de 1950. A fábrica foi fundada pelo italiano Giuseppe Zappi, no bairro da Vila Prudente, em São Paulo, em 1918. Acervo Museu Paulista da USP.

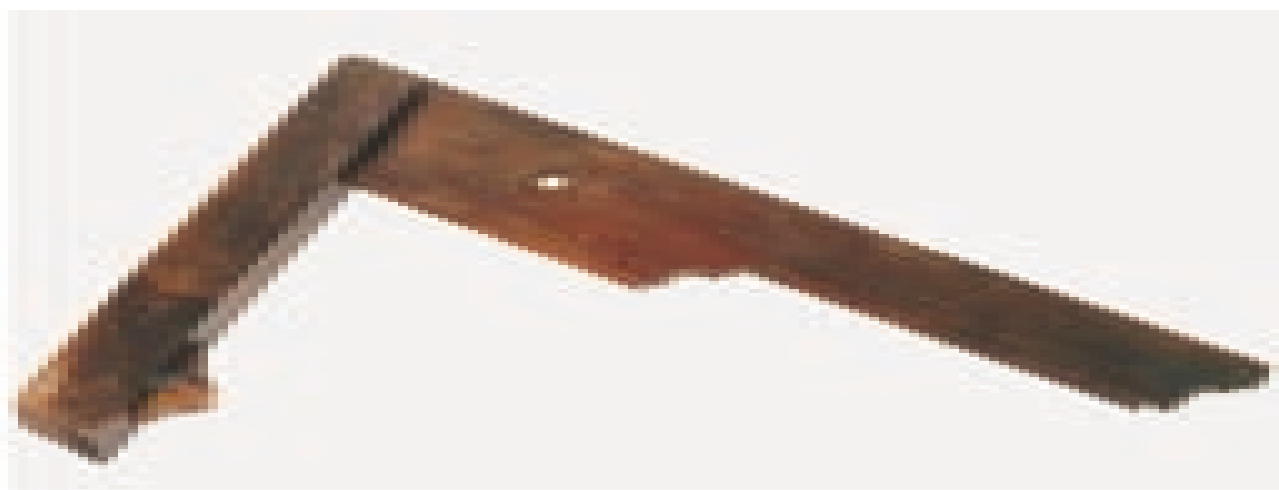

FIGURA 18 - Esquadro de madeira encontrado nas escavações do sub-solo do Museu Paulista, em 1996. Acervo Museu Paulista da USP. 
mantidos nos diferentes museus e coleções. Alguns autores consideram que só fazem parte da numismática tradicional os estudos relativos a cunhagens regulares e oficiais, remetendo as outras possibilidades para outros campos, como a história econômica ou da arte, por exemplo.

Mas, do nosso ponto de vista, as trocas entre os homens envolvendo moeda, sempre foram objeto específico de estudo e reflexão para historiadores-numismatas.

A troca implica um valor imaginário convencionado entre as partes padrão de valor -, e as formas de se efetuar essas trocas variam consideravelmente, de sociedade para sociedade. A fim de otimizar essas relações, os homens inventaram a moeda que, na definição de Aristóteles (ed. 1991, p. 88), é uma mercadoria intermediária, que serve para facilitar as trocas. Assim, o dinheiro se presta para medir ou quantificar as coisas, igualar o que é desigual.

Os poderes públicos, cientes dos lucros que poderiam obter com essa invenção, monopolizaram o direito de emitir moedas (BAUDIN, 1940, p. 12). O Estado não é o criador da moeda, ele apenas formaliza a preferência da opinião pública, uniformizando o numerário sem necessidade de pesagens e variações de câmbio.

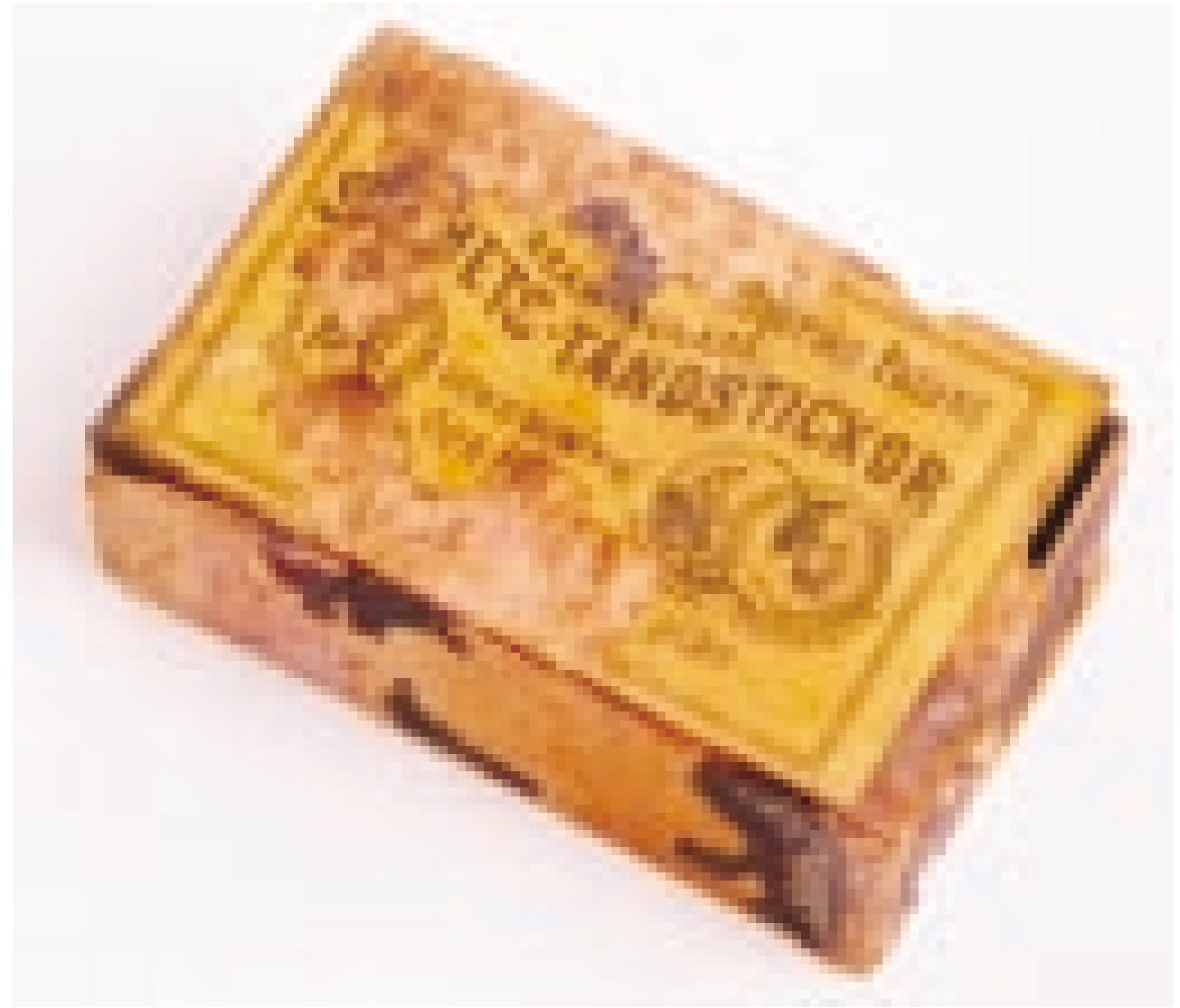

FIGURA 19 - Caixa de fósforos e rótulo, do final do século XIX, de fabricação sueca, marca Jonköpings, encontrados nas escavações do sub-solo do Museu Paulista, em 1996. Acervo Museu Paulista da USP. 
mesmo pode-se dizer do papel-moeda, que é uma promessa escrita de pagar, ao portador e à vista, certa quantidade de numerário em espécie, isto é, na moeda real do país.

monopólio deste poder foi muitas vezes desafiado, e até suplantado pela sociedade, que efetivamente faz uso da moeda para viabilizar suas trocas cotidianas, visando à sobrevivência. $\bigcirc$ Estado não consegue impor moeda que não seja do agrado do público, porém entre esse público circulam moedas que estão fora de qualquer intervenção do Estado. É nessa linha de raciocínio que se incluem nossas pesquisas sobre as formas alternativas de dinheiro. Foi também, por certo, essa concepção que norteou o historiador Taunay quando adquiriu para o acervo do Museu Paulista, em meados da década de 1920, a coleção de vales particulares em papel.

Essa coleção é formada por vales que eram convertidos em produtos ou serviços, emitidos por casas comerciais ou pessoas físicas, procedentes de diversos Estados do Brasil. Constam dessa coleção, também, propagandas em forma de dinheiro, bilhetes de companhias de trens e bondes, fichas de controle de entrada e saída em fábricas ou fazendas e fichas de trabalho diário. Esses vales só deveriam circular em um local predeterminado e sua conversão só deveria ser feita pelo emissor, sendo proibida sua utilização para outros fins. Porém, na prática, o que ocorria é que esses vales passavam a circular de mão em mão, fazendo as vezes de moeda (FIGURAS 3 - 6).

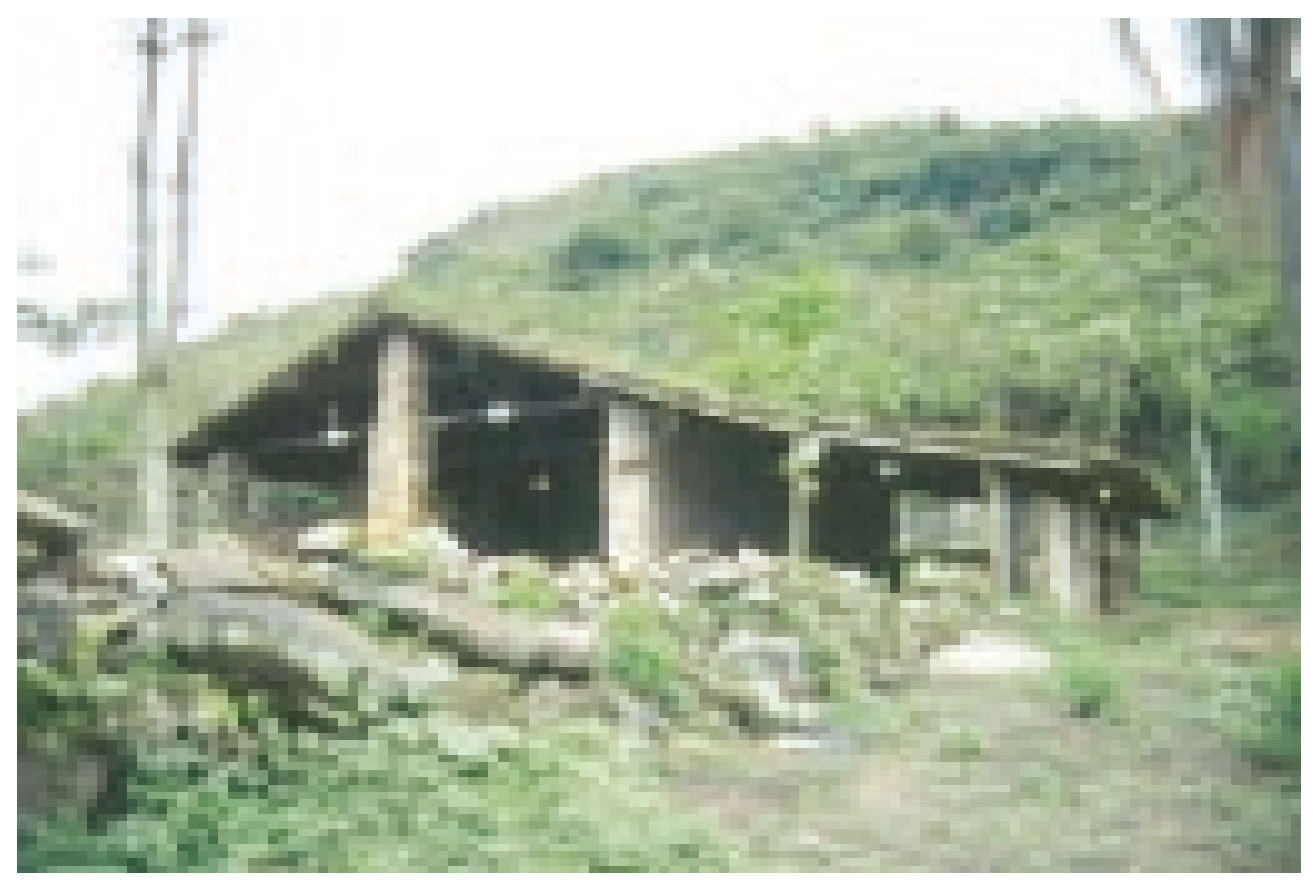

FIGURA 20 - Aspecto do sítio arqueológico Engenho São Jorge dos Erasmos, em Santos, SP. Acervo Museu Paulista da USP. 
Outra forma oficiosa de dinheiro foram os carimbos particulares apostos em dinheiro oficial. Pesquisas sobre esse tema resultaram já em dissertação de mestrado com o título Carimbos particulares nas moedas do Brasil Império: formas alternativas de dinheiro (RIBEIRO, 1997; 1999), onde se discute se a função dessas moedas era puramente econômica - servir de troco - ou se havia uma intenção política de afirmação da posição social daqueles que faziam uso do expediente de emitir ou carimbar moedas.

Durante o ano de 2003 ingressou no acervo uma coleção de Notgeld literalmente, dinheiro de emergência - formada de 330 cédulas emitidas na Áustria e Alemanha, a maioria entre os anos de 1913/1920, porém incluindo também cédulas emitidas no período do nazismo (FIGURAS 7 - 9). Embora tal coleção não contenha dinheiro de emergência produzido no Brasil, sabe-se, através da bibliografia (GINTNER, 2003; LUDOF, 1948, 1968; MEILLI, 1903; PROBER, 1960 entre outros), de mais de uma experiência neste sentido, sendo desejável que nos próximos anos se consigam peças representativas desse fenômeno também em território nacional.

A emissão dessas cédulas se justifica, mais comumente, pela escassez da emissão de dinheiro oficial, à qual o público reage produzindo seu próprio instrumento de troca. Aqui, também, pode-se questionar se a função é puramente econômica, pois é sabido que as comunidades ou cidades que emitiam essas cédulas rivalizavam entre si para produzir as mais belas peças. $\bigcirc$ que estaria movendo essa rivalidade? Será somente a demonstração da perfeição técnica das gráficas responsáveis pela fabricação das cédulas? Quanto aos motivos

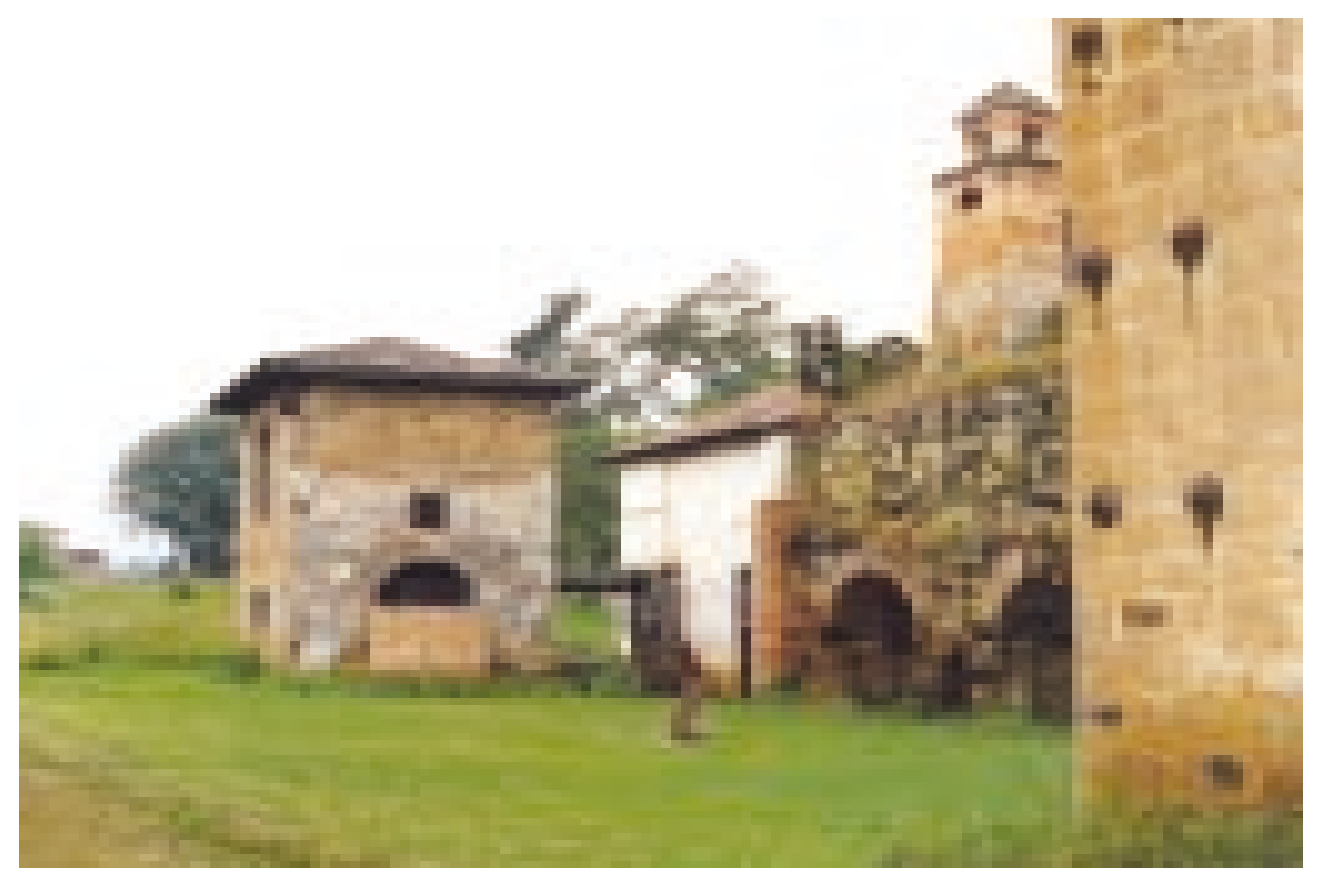

FIGURA 21 - Aspecto do sítio arqueológico Fazenda lpanema, em Iperó, SP. Acervo Museu 


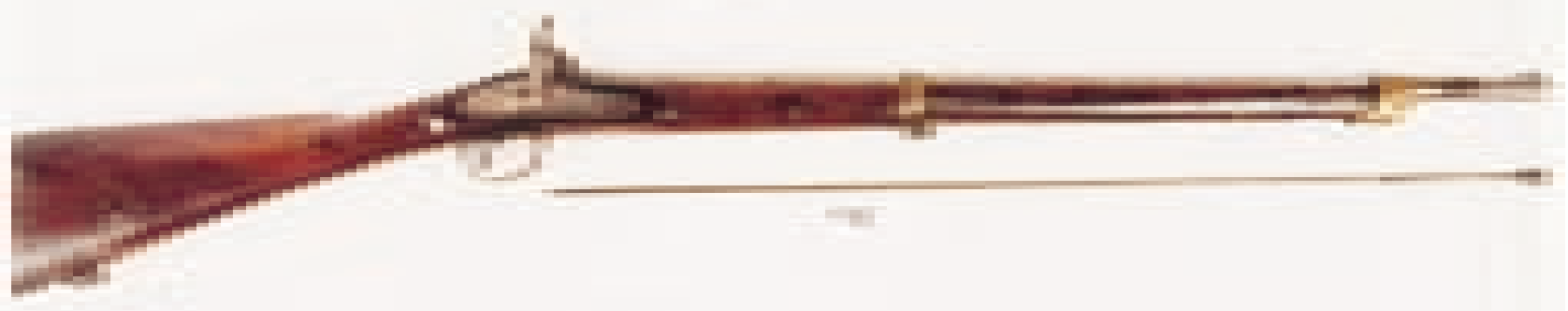

FIGURA 22 - Fuzil Minié, de fabricação belga, meados do século XIX. Acervo Museu Paulista da USP.

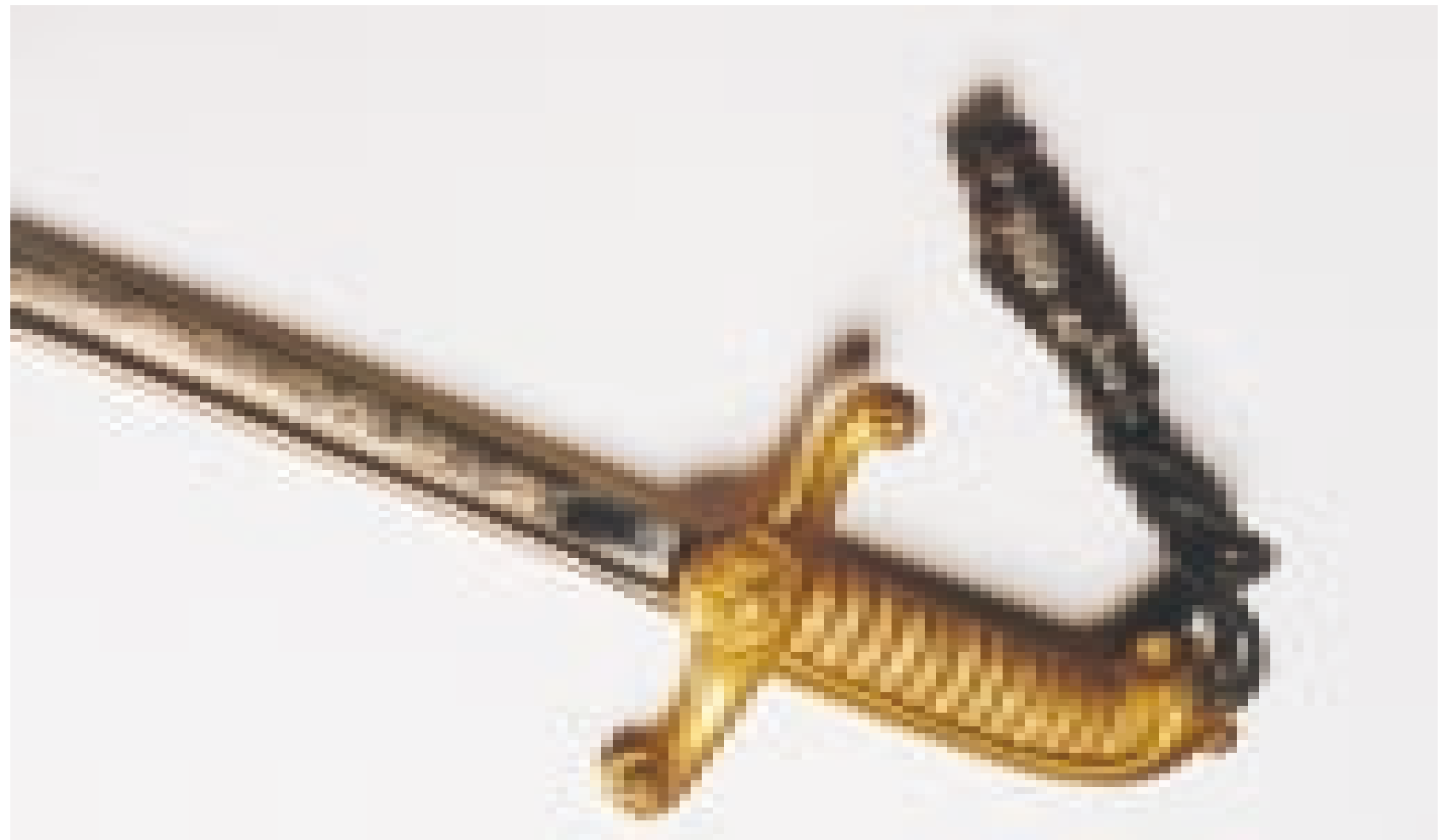

FIGURA 23 - Espada do General Bertoldo Klinger - um dos líderes militares da Revolução de 32 -, com símbolo da República brasileira e a inscrição A ESCOLA DE RIO PARDO AO DISTINCTO ALUNNO BERTHOLDO KLINGER. Acervo Museu Paulista da USP. 
iconográficos utilizados, que sentidos teriam? São questões que podem ser levantadas e desenvolvidas a partir das coleções existentes no Museu Paulista.

Sublinha de pesquisa 3 - Cultura Visual no século XIX: museus, exposições industriais e cidades

Centrada na História da Cidade de São Paulo, levando em conta relações com matrizes européias, visa à compreensão de dinâmicas transculturais no processo modernizador. Examina, para tanto, desde a circulação de objetos de consumo até questões urbanísticas, passando por diversos âmbitos em que se deu a prática das exposições como expressões materiais de novas concepções de mundo, como sistemas cognitivos visualmente apreensíveis e seu significado em mudanças sociais.

Na década de 1990, pesquisa em torno da Exposição Universal de 1889, em Paris, examinou o estabelecimento de uma cultura visual própria à sociedade industrial, que criou uma retórica sensorial, veiculadora de seu ideário e seus valores, e na qual o objeto industrial tem lugar privilegiado (BARBUY, 1999). Mais recentemente, foram desenvolvidas pesquisas em torno da relação entre cultura visual urbana, cosmopolita, e comércio/consumo de bens materiais, buscando-se a especificidade local do fenômeno na cidade de São Paulo, vista em seu movimento de inserção no sistema internacional (BARBUY, 2001).

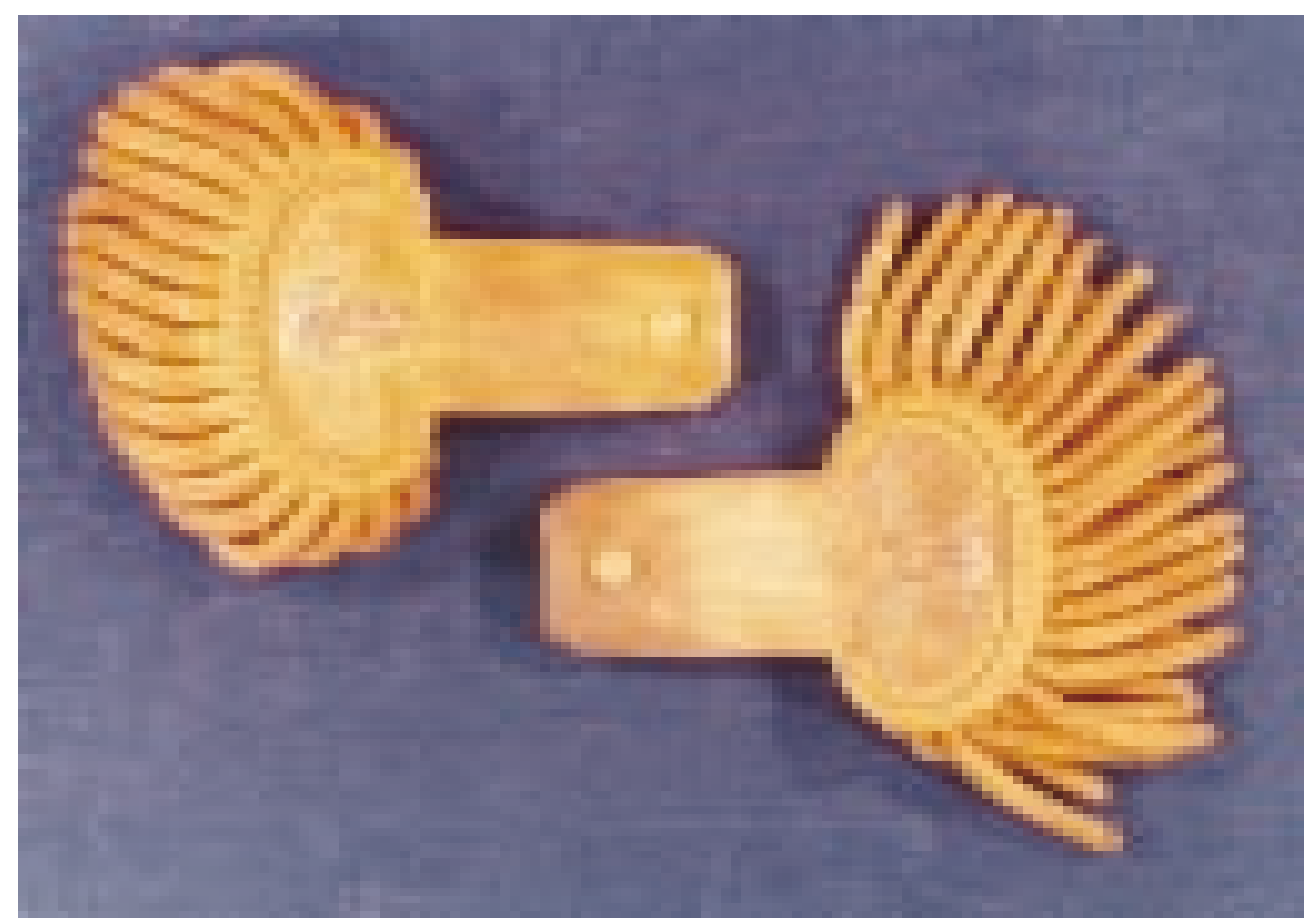

FIGURA 24 - Par de dragonas do uniforme do Almirante João B. das Neves. Acervo Museu 


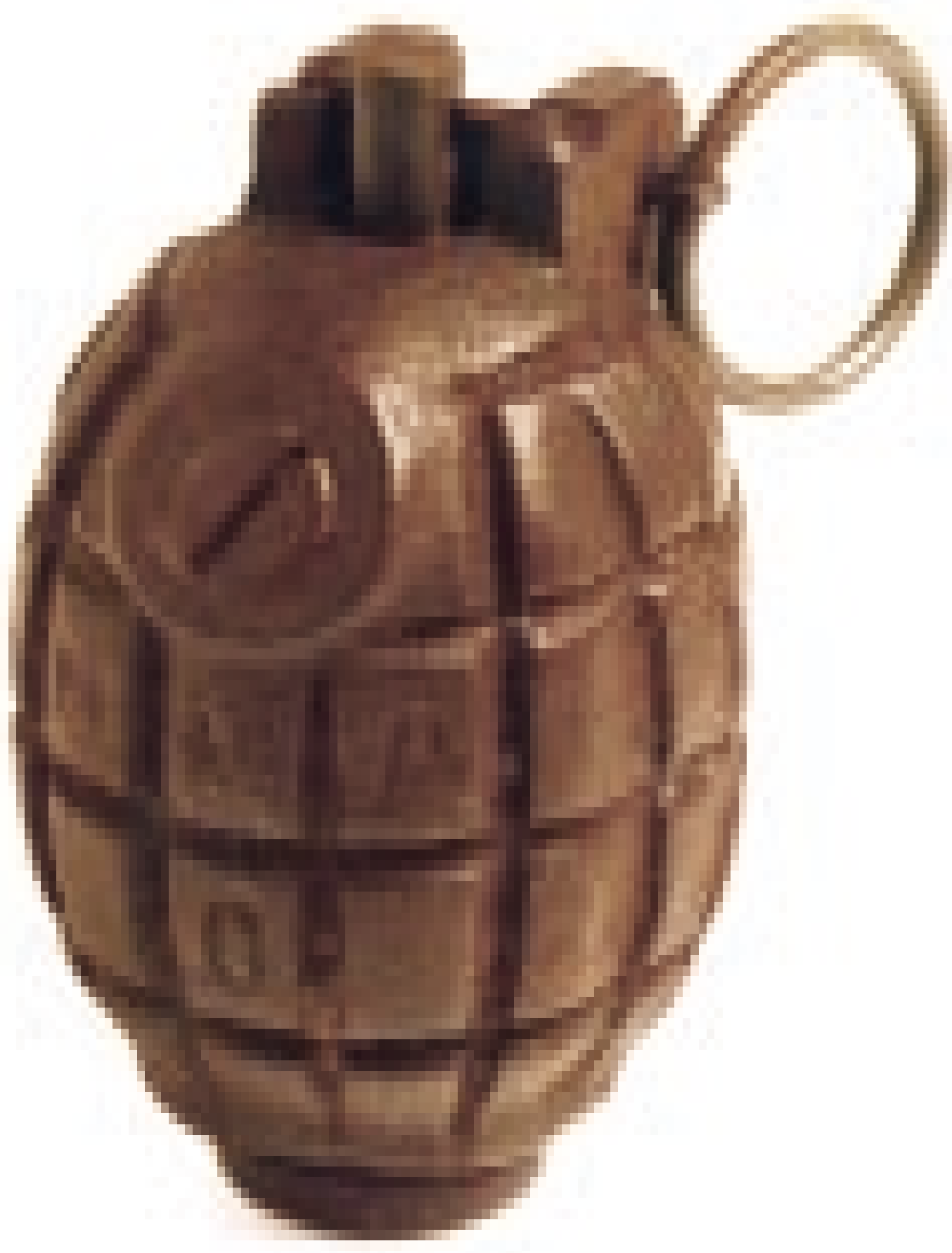

FIGURA 25 - Granada de mão das tropas do Movimento Constitucionalista de 1932. Acervo Museu Paulista da USP. 
7. Ludmila Érica Cambusano de Souza. Comércio, circulação e fabricação de brinquedos em São Paulo, 19011937. Iniciação Científica em curso, de realização, no Museu Paulista, sob a orientação de Heloisa Barbuy (prevista para finalização em dez. 2004).
Ramificação 3.1 - Comércio, industrialização e cultura material

A eleição, no Museu Paulista, do centenário decorrido entre 1850 e 1950 como período preferencial para as pesquisas institucionais, teve sobre o acervo de objetos alguns efeitos essenciais: o primeiro deles foi uma intensificação das pesquisas e catalogações relativas aos objetos do final do século XIX e início do $X X$, ligados, em sua maioria, a um comércio de importação, que constituíam já a maior parte do acervo e foram ainda fomentados com quantidade considerável de novas aquisições; o segundo foi a abertura para um período até ali descuidado, 1914-1950, que corresponde justamente ao processo de grande crescimento econômico do Estado de São Paulo. Nele se detecta a vitalidade de um sem número de experiências fabris em diversos ramos de produção e que desembocaram, nos anos 30 e 40, na projeção das primeiras grandes indústrias nacionais.

A fase das primeiras experiências fabris do século XX em São Paulo é campo de pesquisa praticamente virgem no que diz respeito à Cultura Material. Já foi amplamente desenvolvido na História Econômica e na História Social da industrialização e do trabalho, mas sob a óptica da macro-história, que busca a compreensão dos grandes processos. Vê-se agora que muito há ainda a conhecer e refletir sobre a micro-história tecida nas trajetórias dos pequenos empreendimentos fabris e na gama de objetos por eles produzidos. Estes últimos, mesmo que muitas vezes pertencentes a categorias economicamente irrelevantes, puderam ter função difusora e emblemática no mundo urbano ou doméstico. De fato, é caminho descoberto para ampliar-se o conhecimento sobre o universo a um tempo material e simbólico dos objetos industrializados.

Diz Daniel Roche, em sua História das coisas banais, que

[..] se admitirmos que o mundo exterior dos objetos não é o espaço de nossa total alienação mas o meio para um processo criativo, e que a relação dos indivíduos com o sociál passa pela reificação, a história do consumo permitirá melhor compreender a continuidade que vai do material ao simbólico, o esforço de inteligência e de trabalho cristalizado que se conserva num simples objeto, a união das representações e das realidades (ROCHE, 1997, p. 16).

Mas como fazer pesquisas nesse sentido, em História e Cultura Material, se pouco se conhece sobre a história local do consumo em São Paulo? Sabe-se apenas em linhas gerais que no período em questão houve uma grande circulação de novos objetos industrializados, inicialmente importados, que invadiram todos os ambientes sociais. E que foi o próprio processo comercial de importações que, no caso de São Paulo, alavancou a indústria local (DEAN, [s.d.]). Pouco se sabe até mesmo sobre a natureza de tais objetos em circulação. Assim, é para mapear o universo de objetos categorizados como "bens de consumo" que se estenderam pelas teias do processo de expansão da sociedade industrial ocidental e da formação de uma sociedade de consumo entre nós, que se criou esta ramificação na referida sublinha de pesquisa. Para melhor conhecer esse universo, busca-se inicialmente no estudo da produção, a recuperação de informações sobre a gama seriada de objetos fabricados em São Paulo desde o final do século XIX até 1950, com recorte espacial na capital e região.

Nesta sublinha foi já produzida uma pesquisa de Iniciação Científica (PEREIRA, 2002), estando outra em andamento 7 (FIGURAS 10-11). O conhecimento gerado por tais trabalhos contribui também para o estabelecimento de critérios de 
coleta de novos acervos. Relacionam-se, ainda, com as catalogações do Banco de Dados, que prevêem o preenchimento de campos relativos a casas comercializadoras e/ou fabricantes de cada objeto e, no histórico, entre outras, com informações relativas a esses estabelecimentos. A esse respeito, a catalogação de algumas coleções avançou especialmente ${ }^{8}$ (FIGURAS 12 - 15).

Particularmente no que se refere aos objetos de uso doméstico em faiança e porcelana, lque, no thesaurus acima citado, em sua grande maioria estão inseridos na categoria de objetos relacionados ao "Processamento da alimentação - Serviço/consumo"), foi criado, em janeiro de 2002, o Grupo de Estudos de Faianças e Porcelanas", que tem como objetivo o desenvolvimento de conhecimentos sobre esse tipo de objeto, desde seus aspectos técnico-produtivos até seus usos sociais, na perspectiva da Cultura Material.

Voltadas para a louça produzida em São Paulo lem relação à qual havia uma lacuna não somente no acervo do Museu Paulista, mas como campo para pesquisas de um modo geral), realizam-se visitas técnicas a fábricas e museus, entrevistas e coletas de acervo (FIGURAS 16 - 17).

Os trabalhos incluem os tratamentos de higienização e acondicionamento das peças, que se fazem associados à marcação dos números de tombo, ao controle administrativo do acervo e à produção de reportagens fotográficas de cada objeto, estas sendo inseridas na galeria de imagens do banco de dados ${ }^{10}$.

Sublinha de pesquisa 4 - Arqueologia Histórica e Industrial

\section{Memória da Arqueologia Histórica e Industrial no Museu Paulista}

Um projeto foi elaborado a fim de organizar toda a documentação textual e iconográfica resultante de pesquisas realizadas desde 1976, desenvolvidas e/ou coordenadas por Margarida Davina Andreatta, em convênios do Museu Paulista com outras instituições brasileiras. Para tanto, organizam-se dossiês completos sobre cada projeto, que ficarão depois disponíveis para a consulta de outros pesquisadores (Quadro 1) 11. (FIGURAS 18, 19)

\section{Arqueologia Industrial}

Experiências fabris desenvolvidas no período colonial são objeto de pesquisas em Arqueologia, visando à ampliação de conhecimentos sobre a história da industrialização no Brasil. São dois os principais projetos nessa área, baseados em sítios arqueológicos de relevância incontestável: um deles é o Engenho São Jorge dos Erasmos, no município de Santos/SP; o outro é a Fazenda lpanema, em lperó/SP.

Engenho São Jorge dos Erasmos - engenho para fabricação de açúcar que data do século XVI (construído provavelmente em 1534), é patrimônio cultural pertencente à Universidade de São Paulo desde 1943. Atualmente vem recebendo grande atenção da Pró-Reitoria de Cultura e Extensão, que coordena diversos trabalhos com o objetivo de revitalizar o sítio, tanto no sentido de preservá-lo como de qualificá-lo para uso cultural ${ }^{12}$. Uma das principais frentes do projeto é a
8. Cite-se o caso das porcelanas estrangeiras, que se beneficiou de trabalhos iniciais de catalogação de Suzana César Gouveia Fernandes, primeiro como estagiária (com bolsa Fundap - 1991-1992) e depois, como jovem historiadora, para um estudo de marcas (com apoio do Fundo de Pesquisas do Museu Paulista - 1999) e, mais recentemente, do alentado trabalho da estagiária Joana Cabete Biava, que durante 20 meses avançou extraordinariamente na pesquisa documental dessa coleção e respectiva catalogação no Banco de Dados (com bolsa do Fundo da Pró-Reitoria de Cultura e Extensão 2002-2003), ambas sob orientação de Heloisa Barbuy.

9. Heloisa Barbuy (coord.), Margarida Davina Andreatta (assessora), Rosana Gimenes Aguilera (técnica de museu), Marizia Tonelli (mestranda em Arqueologia), José Hermes Martins Pereira (pesquisador de Iniciação Científica em História com bolsa da FAPESP 2002), Joana Cabete Biava (bolsista do Fundo de Cultura e Extensão, 20022003).

10. Os trabalhos técnicos relativos a essa coleção são desempenhados pela técnica Rosana Gimenes Aguilera, que para os aspectos de conservação atua sob a orientação da restauradora Yara Lígia M.M.Petrella (Laboratório de Conservação e Restauro do Museu Paulista), e no que tange à produção de fotografias, em interação com o fotógrafo Hélio Nobre, com a colaboração de Vagner Gusmão (Divisão de Difusão Cultural do Museu Paulista). 
11. Este projeto vem sendo realizado por Margarida Davina Andreatta e Marizia Tonelli.

12. Para tanto foi firmado convênio entre a USP e a Prefeitura Municipal de Santos.

13.Tais pesquisas resultaram de um protocolo de intenções assinado entre o Museu Paulista e o Ministério da Agricultura, este através do Centro Nacional de Engenharia Agrícola - CENEA, extinto em 1990

14.Anicleide Zequini (historiadora da industrialização no interior do Estado de São Paulo e documentalista do Museu Republicano "Convenção de Itu"-MP/USP). A siderurgia do século XVI ao XVIII, na Vila de São João de Ipanema, em Iperó/SP. Doutorado em andamento pelo MAE/USP, sob a orientação de Margarida Davina Andreatta.
Quadro 1 - Memória da arqueologia histórica e industrial. Projetos desenvolvidos pelo Museu Paulista de 1976 a 2002

\begin{tabular}{|c|c|c|}
\hline No. & PERÍODO & NOME DO DOSSIÊ \\
\hline 01 & 1974 & Prospecção Fazenda Periquito \\
\hline 02 & $1975-1990$ & Projeto Anhanguera de Arqueologia - GO \\
\hline 03 & 1979 & Prospecção Arq. Sitio Ressaca \\
\hline 04 & $1979-1980$ & Arq. Hist. Casa Bandeirista do Tatuapé - SP \\
\hline 05 & $1980-1987$ & Arq. Hist. Sítio Morrinhos - Jardim S. Bento \\
\hline 06 & 1980 & Salvamento Arq. em Mogi Guaçú \\
\hline 07 & 1980 & Arq. Hist. Casa No.1do Páteo do Colégio \\
\hline 08 & 1980 & Arq. Hist. Vale do Anhangabaú \\
\hline 09 & 1980 & Arq. Hist. Casa da Marquesa \\
\hline 10 & $1981-1983$ & Arq. Hist. Casa do Grito - Ipiranga \\
\hline 11 & $1983-89$ & Fazenda Ypanema Iperó \\
\hline 12 & $1986-1988$ & Caieira do Brasil Colônia \\
\hline 13 & $1986-1987$ & Arq. Hist. Sítio Mirim - Ermelino Matarazzo \\
\hline 14 & 1987 & Prospecção Ruínas de Abarebebê \\
\hline 15 & 1988 & Vistoria Arq. Teatro Municipal \\
\hline 16 & 1988 & Arq. Histórica Casa do Itaim Bibi \\
\hline 17 & 1988 & Vistoria Arq. Porto das Naus \\
\hline 18 & 1989-1992 & Batatais MP/COMPHAC - SP \\
\hline 19 & 1990-1992 & Arq. Hist. Bairro da Fundação \\
\hline 20 & $1990-1996$ & Museu Paulista- Ypiranga Séc XIX ( subsolo) \\
\hline 21 & 1990 & Vistoria Arq. Calçada do Lorena \\
\hline 22 & 1990 & Proj. Recuperação Outeiro S. Catarina \\
\hline 23 & 1990 & Prospecção Arq. Barra do Itaguaré \\
\hline 24 & $1992-1993$ & Proj. de Arq. Pré-Hist. \\
\hline 25 & 1994 & Vistoria Arq. em Barro Branco \\
\hline 26 & 1994 & Proj. de Arq. Hist. Agência Eletropaulo \\
\hline 27 & 1994-2002 & Proj. de Arq. da Serra do Itapety \\
\hline 28 & 1994 & Prospecção Arq. Sambaqui do Ouro \\
\hline 29 & 1996-2002 & Proj.Engenho São Jorge dos Erasmo \\
\hline 30 & 1997 & Vistoria Arq. em Silveiras \\
\hline 31 & 1998-1999 & Vistoria Arq. Sítio Casa da Pedra \\
\hline 32 & 1998 & Vistoria Arq. em Paranapiacaba \\
\hline 33 & 1998 & Prosp. Arq. Sítio Bacharel Cosme Fernandes \\
\hline 34 & 2000 & Vistoria Arq. Engenho Novo \\
\hline 35 & 2001 & Prosp. Arq. Aldeia Tekoá-Ytu \\
\hline 36 & 2002 & Prosp. Arq. Casa no. 80 \\
\hline
\end{tabular}

\begin{tabular}{|c|c|c|}
\hline \multirow[t]{2}{*}{ LOCAL } & \multicolumn{2}{|c|}{ ACERVO } \\
\hline & DOCUMENTAL & MATERIA \\
\hline - Parapuã & Sim & Não \\
\hline - Goiânia & Sim & Sim \\
\hline - Capital & Sim & Não \\
\hline - Capital & Sim & Sim \\
\hline - Capital & Sim & Sim \\
\hline - Mogi Guaçú & Sim & Não \\
\hline - Capital & Sim & Sim \\
\hline - Capital & Sim & Sim \\
\hline - Capital & Sim & Sim \\
\hline - Capital & Sim & Não \\
\hline - Iperó & Sim & Não \\
\hline - Cubatão & Sim & Não \\
\hline - Capital & Sim & Sim \\
\hline - Peruibe & Sim & Não \\
\hline - Capital & Sim & Não \\
\hline - Capital & Sim & Sim \\
\hline - São Vicente & Sim & Não \\
\hline - Batatais & Sim & Não \\
\hline - S.C.do Sul & Sim & Não \\
\hline - Capital & Sim & Sim \\
\hline - Capital & Sim & Não \\
\hline - Santos & Sim & Não \\
\hline - Bertioga & Sim & Não \\
\hline - Paranaguá & Sim & Não \\
\hline - Barro Branco & Sim & Não \\
\hline - Itu & Sim & Não \\
\hline - Mogi das Cruzes & Sim & Não \\
\hline - Joinville & Sim & Não \\
\hline - Santos & Sim & Não \\
\hline - Silveiras & Sim & Não \\
\hline - Santana de Parnaíba & Sim & Não \\
\hline - Paranapiacaba & Sim & Não \\
\hline - S.Vicente & Sim & Não \\
\hline - S. B. do Campo & Sim & Não \\
\hline - Capital & Sim & Não \\
\hline - Santana de Parnaíba & Sim & Não \\
\hline
\end{tabular}

retomada das pesquisas arqueológicas ali iniciadas em 1996, sob a coordenação de Margarida Andreatta, que agora lhes dá continuidade, realizando trabalhos de decapagem e escavação, necessários para evidenciar a estrutura original da edificação (FIGURA 20).

Fazenda lpanema - pesquisas realizadas de 1983 a $1988^{13}$, sob a coordenação de Margarida Andreatta, geraram coletas de material arqueológico, documentação cartográfica, fotografias, anotações de campo e a descoberta de outras estruturas arqueológicas, que estão sendo agora retomadas em um projeto de doutorado ${ }^{14}$. A Fazenda lpanema, hoje integrada à Floresta Nacional de Ipanema (considerada como área de proteção ambiental), inclui sítios históricos nos quais se conservam edifícios da Fábrica de Ferro lpanema do século XIX e 
ruínas de forjas e fornos que, calcula-se, datam dos séculos XVI-XVIII. Tal patrimônio foi revalorizado por ocasião das comemorações realizadas no ano 2000, relativas à chegada dos portugueses ao Brasil, o que gerou uma renovação do interesse em dar continuidade às pesquisas por parte dos responsáveis por aquele patrimônio, criando-se as condições necessárias para que o Museu Paulista venha a retomar o projeto (FIGURA 21).

Sublinha de pesquisa 5 - Vida militar e cultura material

Os equipamentos militares ${ }^{15}$ do Serviço de Objetos do Museu Paulista constituem uma das coleções mais significativas da instituição. Tipologicamente, há uniformes (principalmente da Guarda Nacional, da Força Pública de São Paulo e das corporações antecessoras desta como os Permanentes, a Guarda Urbana, a Guarda Cívica e outras; há também uniformes civis, em especial, de ministros e senadores do Império); armas (espadas, armas de fogo portáteis de cano curto e cano longo e alguns canhões); acessórios de armaria (polvarinhos, cobre-miras, bainhas, etc.); munições (em sua maioria oriundas das tropas do Movimento Constitucionalista de 1932); insígnias (dragonas, platinas, bandas, topes, medalhas, etc.) (FIGURAS 22 - 27); objetos com referências à vida militar, por exemplo, moedas com efígies de militares ou de temas militares; objetos pessoais que pertenceram a militares - é o caso de peças de serviços de porcelana que foram de coronéis da Guarda Nacional.

A quantidade e variedade destes acervos faz supor que provavelmente desde a fundação do Museu Paulista são bastante valorizados. Há registros da entrada tanto de unidades avulsas quanto de uma coleção privada como a do coronel Ernesto de Oliveira (em 1935) e de um acervo já constituído como o do antigo Museu da Força Pública (em 1948), além da formação ao longo do tempo de coleções como "Revolução de 32" e "Guerra do Paraguai".
15. Empregamos o termo "militar" numa acepção ampla, fazendo referência não só a tropas regulares da primeira linha como o Exército, mas a tropas auxiliares e contingentes policiais, ou seja, a associações e corporações armadas.

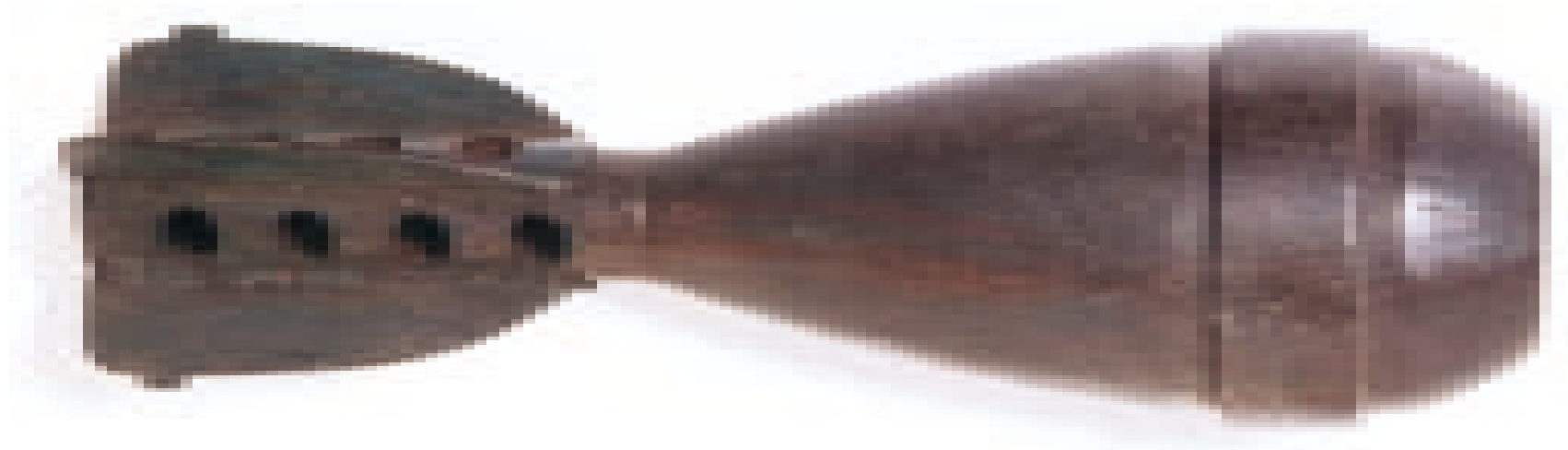

FIGURA 26 - Bomba de bombarda das tropas do Movimento Constitucionalista de 1932.

Acervo Museu Paulista da USP. 
É do artista-documentarista e também especialista em armas José Wasth Rodrigues a primeira iniciativa para tratamento sistemático dos registros sobre este acervo, elaborando fichas catalográficas nas quais se vê a preocupação com a precisa denominação das unidades e sua descrição normatizada e detalhada. Posteriormente, na reorganização da Reserva Técnica, em 1984, a armaria recebeu um mobiliário próprio para acondicioná-lo. Na mesma época, numa projetada implantação de novos padrões de controle da movimentação de peças, foi organizado um sistema de localização para todo o acervo, e apenas um em separado, para as armas. São controles operacionais e administrativos, não-sistemáticos, que representam uma preocupação difusa mas efetiva com este tipo de acervo.

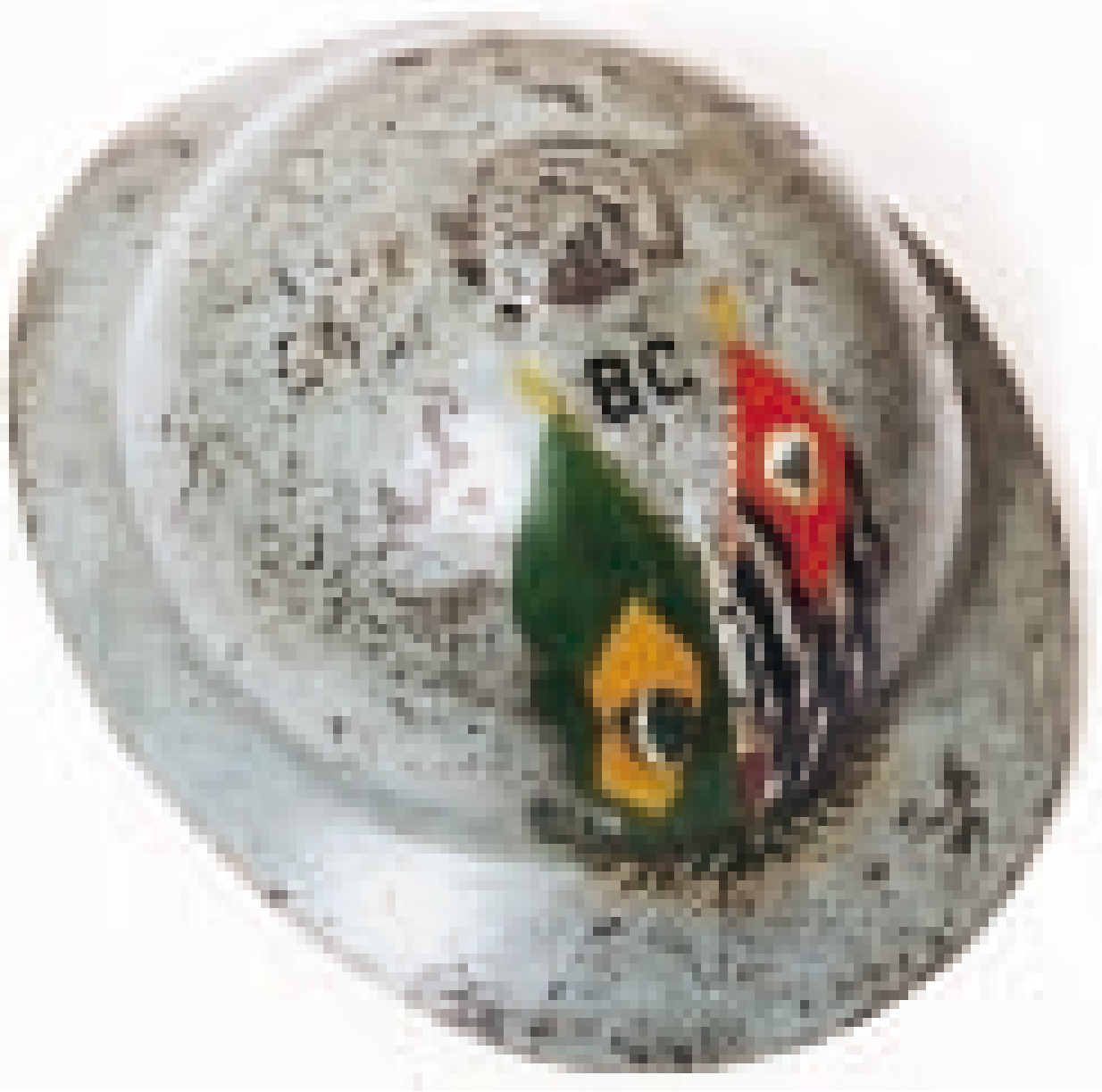

FIGURA 27 - Capacete das tropas do Movimento Constitucionalista de 1932, com a imagem das bandeiras do Brasil e de São Paulo entrelaçadas e encimadas pela inscrição "BC". Internamente possui as seguintes inscrições: "OFFERTA DO POVO PAULISTA AO SOLDADO DA CONSTITUINTE"; manuscrito: "C.G.B. CHICO" / "Mantiqueira 12.03.32". Acervo Museu Paulista da USP. 
Recentemente, estes acervos começaram a constituir objeto de estudos acadêmicos, um dos desenvolvimentos das linhas de pesquisa implantadas pelo Plano Diretor de 1990. Uma dissertação de mestrado, na qual se estudam uniformes da Guarda Nacional a partir da análise de exemplares do acervo do Museu, foi defendida (ALMEIDA, 1999), e uma tese de doutorado está em andamento, com término previsto para $2007^{16}$

Em ambos os casos há uma preocupação metodológica que diz respeito à abordagem dos objetos físicos como fontes materiais para a pesquisa, e que está associada à questão da apropriação social de artefatos. Isto significa afirmar que funções, formas e sentidos dos artefatos são examinados, ao mesmo tempo, como resultado e ingredientes do desenvolvimento e transformações de relações sociais. No caso dos uniformes militares, notadamente da Guarda Nacional, este encaminhamento geral permitiu analisá-los como recursos materiais que civis arregimentados para serviços militares utilizavam na organização interna da milícia para o desenvolvimento de relações de dependência lentre um senhor e sua clientela), um dos eixos fundamentais da organização social brasileira que, nesta pesquisa específica, é analisado durante o Segundo Reinado laté o início da Guerra do Paraguai). Já em relação às armas de fogo, enfoques promissores que iá se podem delinear são o impacto da tecnologia do armamento sobre as estratégias de guerra e as formas de mobilização do corpo do soldado, e a arma como dispositivo de sinalização de apropriação individualizada de equipamento institucional e de fabricação em série. São desenvolvimentos iniciais que se procura inserir no âmbito dos estudos sobre vida militar, com o propósito de fornecer novas possibilidades de compreensão e perspectivas de análise a partir da cultura material.

Em suma, as atividades do Serviço de Objetos voltam-se, em sentido amplo, a uma melhor compreensão dos contextos socioculturais nos quais se deu a produção, circulação e consumo (aqui incluídos os usos pragmáticos e simbólicos) daquela tipologia de objetos que é o seu eixo documental. É na dimensão material da cultura - a um tempo concretude e representação - que se busca conhecer e interpretar a história da sociedade brasileira, muito especialmente de suas conjunturas paulistas.

\section{REFERÊNCIAS}

ALMEIDA, Adilson José. Uniformes da Guarda Nacional, 1831-1852; a indumentária militar na organização e funcionamento de uma associação armada. 1999. 251 p. Dissertação (Mestrado) Faculdade de Filosofia, Letras e Ciências Humanas, Universidade de São Paulo, São Paulo, 1999p.

\section{ARISTÓTELES. Ética a Nicômaco (Livro V). São Paulo: Nova Cultural, 1991.}

BARBUY,Heloisa. A Cidade-Exposição: comércio e cosmopolitismo em São Paulo, 1860-1914.2001. 169 p.Tese (Doutorado) - Faculdade de Arquitetura e Urbanismo, Universidade de São Paulo, São Paulo, 2001. Prevista publicação pela Edusp, no $1^{\circ}$ sem. 2004, Selo “450 Anos de São Paulo”.

Dossiê: veículos terrestres. São Paulo: Museu Paulista, 2000. 2v. Instrumento de pesquisa datilografado.
16. Por Adilson José de Almeida, sob o título provisório de Armas de fogo de tropas militares do Império brasileiro. 
A Exposição Universal de 1889 em Paris: visão e representação na sociedade industrial. São Paulo:História Social USP/Loyola, 1999. (Série “Teses”). Originalmente Dissertação de Mestrado.

BARBUY, Heloisa; LIMA, Solange Ferraz de; CARVALHO, Vânia Carneiro (Coord.). O sistema documental do Museu Paulista: a construção de um banco de dados e imagens num museu universitário em transformação/Le système documentaire du Musée Paulista :la construction d'une banque de données et d'images dans un musée universitaire en transformation. In: OLIVEIRA, Cecilia H. S.; BARBUY, Heloisa (Org.). Imagem e produção de conbecimento. São Paulo: Museu Paulista, 2002. p.13-29. Seminário realizado no Museu Paulista da USP, São Paulo, 1-2 out. 2001, como parte integrante dos 18 èmes Rencontres internationales Image \& Science do CNRS-Paris.

BASSO, Marisa. A Revolução de 32 no acervo de objetos do Museu Paulista. São Paulo: Museu Paulista, 1999. 142 p. il. Instrumento de pesquisa datilografado.

BAUDIN, L. A moeda. São Paulo: Martins, 1940.

DEAN,Warren.A industrialização de São Paulo (1880-1945).Tradução por Octavio Mendes Cajado. 3. ed. São Paulo: Difel, [s.d.].

GINTNER, Luiz J. O Tirol brasileiro: uma breve história de Treze Tílias e memórias da primeira infância. 2.ed. Rio de Janeiro:Altiva, 2003.

LUDOLF, Dulce. Moedas particulares e vales metálicos no Brasil. Estudos e documentos. Rio de Janeiro: Museu Histórico Nacional, 1968. pt. 2.

.Estudo das moedas particulares no Brasil.Revista Numismática, Ano XVI, nº 1-4,p. 145-149, 1948.

MARQUES, Mário Gomes. Introdução à numismática. Lisboa: Dom Quixote, 1982.

MEILLI, Julio - A Moeda Fiduciária no Brasil. In: O MEIO circulante nacional.Zurich:Typ. Jean Frey, 1903. pt. III.

PAIXÃO, Giselle Marques Leite. Sistema descritivo para acervos de mobiliário. São Paulo: Museu Paulista, 1999.340 p. il. Instrumento de pesquisa datilografado.

PEREIRA, José Hermes Martins. A implantação da indústria de louça em São Paulo, 1912-1937 (estudo de história na perspectiva da cultura material). Iniciação Científica - Museu Paulista, 2002.

PROBER, Kurt, Carimbos e Moedas Particulares no Brasil. Boletim da Sociedade Numismática Brasileira, n. 4, anexo de 20p., abr. 1960.

RIBEIRO, Angela Maria Gianeze. Monedas reselladas:Dinero alternativo o instrumento de afirmación social? Numisma, Madrid, año XLIX, n. 243, p. 115-139, jul./dic. 1999.

Carimbos particulares nas moedas do Brasil Império: formas alternativas de dinheiro. São Paulo, 1997, 206p. Dissertação (Mestrado) - MAE/USP, Área Interdepartamental deArqueologia.

RIEGL, Alois. Monumentos:valores atribuídos e sua evolução histórica.Tradução por Heloisa Barbuy e Teresa Cristina Toledo de Paula. Revista de Museologia, São Paulo, n.1, p. 17-23, $2^{\circ}$ sem. 1989. 
ROCHE, Daniel. Histoire des choses banales. Naissance de la consommation, XVIIe-XIXe siècle. Paris: Fayard, 1997. p.16.

WASTH RODRIGUES,José. Descrições de mobiliário. São Paulo: Museu Paulista, 1948. Datilografado e rubricado.

Artigo apresentado em 11/2003. 
The two-storey house where Itu Convention was held, in the old Rua do Carmo, Inowadays Rua Barão do ltaim): a documental work of research

Anicleide Zequini Rossi

The text is about the results of a documental work of research (post-mortem inventory and Book of Notes) regarding the trajectory of the building in which The City of Itu (SP)'s Republican Museum (Museu Republicano na Cidade de ltu-SP) is installed, an extension of Museu Paulista - USP. Therefore, from all the pieces of information researched we can infer that the construction day of the building that shelters the museum, is a lot earlier than 1850, year which has been considered as such in many essays. This year registers, in fact, the presence of one of the families that lived in that building: the Almeida Prados that hosted the Conventionals of 1873.

KEYWORDS: Museu Republicano Convenção de Itu - MP/USP. Itu, History. Itu, Museum. Almeida Prado, Family.

Anais do Museu Paulista. São Paulo. N. Sér. v. 10/11.p.197-211 (2002-2003).

De casa a museu: 80 anos do Museu Republicano Convenção de ltu

Jonas Soares de Souza

O texto apresenta um panorama geral do processo de criação do Museu Republicano "Convenção de ltu" na década de 1920. Idealizado pelos republicanos paulistas, o projeto da instituição explorou o valor simbólico da "Convenção de ltu" e o significado do lugar de sua realização como recurso para ampliar a legitimidade histórica da hegemonia do Partido.

PALAVRAS-CHAVE:Arquitetura. Museu. Memória. Comemoração.

Anais do Museu Paulista. São Paulo. N. Sér. v. 10/11.p.213-225 (2002-2003)

From home to museum: 80 years of the Republican Museum (Museu Republicano) ltu Convention

Jonas Soares de Souza

This article presents a general overview of the creation process of Museu Republicano "Convenção de ltu" in the decade of 1920. Idealized by republicans from São Paulo, the institution's project has exploited the Convenção de ltu's symbolic values and the meaning of place where it was made as a resource to widen the historical legitimacy of the Party hegemony.

KEYWORDS:Architecture. Museum. Memory. Celebration.

Anais do Museu Paulista. São Paulo. N. Sér. v. 10/11.p.213-225 (2002-2003)

O Serviço de Objetos do Museu Paulista

Adilson José de Almeida, Angela Maria Gianeze Ribeiro, Heloisa Barbuy, Margarida Davina Andreatta Aborda a organização do Serviço de Objetos do Museu Paulista - curadoria de acervos e sistema de informação - e suas linhas de pesquisa: 1. Formação das coleções. 2. Formas alternativas de dinheiro. 3. Cultura visual no século XIX: museus exposições industriais e cidades / Comércio, industrialização e cultura material. 4. Arqueologia histórica e industrial. 5. Vida militar e cultura material.

PALAVRAS-CHAVE: Curadoria e pesquisa. Numismática. Coleção de veículos. Coleções militares. Cultura visual. Industrialização. Anais do Museu Paulista. São Paulo. N. Sér. v. 10/11.p.227-257 (2002-2003)

The Department of Object Collections of Museu Paulista

Adilson José de Almeida, Angela Maria Gianeze Ribeiro, Heloisa Barbuy, Margarida Davina Andreatta It focuses the organization of the Department of Object Collections of Museu Paulista - curatorship and information system - and its research directions: 1. Formation of the collections. 2. Money alternative forms. 3. Visual Culture in the 19th century: museums, industrial exhibitions and cities / Commerce, industrialization and Material Culture. 4. Historical and Industrial Archaeology. 5. Military life and Material Culture.

KEYWORDS: Curatorship and Research. Numismatic. Collection of Vehicles. Collection of Military Objects. Visual Culture. 